\title{
Seismic Fragility Estimates of LRB Base Isolated Frames Using Performance-Based Design
}

\author{
Iman Mansouri, ${ }^{1}$ Gholamreza Ghodrati Amiri, ${ }^{2}$ Jong Wan $\mathrm{Hu}^{3,4}$ \\ Mohammadreza Khoshkalam, ${ }^{2}$ Sanaz Soori, ${ }^{5}$ and Shahrokh Shahbazi ${ }^{6}$ \\ ${ }^{1}$ Department of Civil Engineering, Birjand University of Technology, Birjand 97175-569, Iran \\ ${ }^{2}$ School of Civil Engineering, Iran University of Science and Technology, Tehran 16765-163, Iran \\ ${ }^{3}$ Department of Civil and Environmental Engineering, Incheon National University, 12-1 Songdo-dong, Yeonsu-gu, \\ Incheon 406-840, Republic of Korea \\ ${ }^{4}$ Head of Center, Incheon Disaster Prevention Research Center, Incheon National University, 12-1 Songdo-dong, Yeonsu-gu, \\ Incheon 406-840, Republic of Korea \\ ${ }^{5}$ Department of Civil Engineering, Shahid Bahonar University of Kerman, Kerman 76169133, Iran \\ ${ }^{6}$ Pooya Sazeh Koohin Co., Ltd., Tehran 18718-13553, Iran
}

Correspondence should be addressed to Jong Wan Hu; jongp24@incheon.ac.kr

Received 29 November 2016; Revised 12 February 2017; Accepted 19 February 2017; Published 11 April 2017

Academic Editor: Longjun Dong

Copyright (C) 2017 Iman Mansouri et al. This is an open access article distributed under the Creative Commons Attribution License, which permits unrestricted use, distribution, and reproduction in any medium, provided the original work is properly cited.

\begin{abstract}
With improving technology, the idea of using energy dissipater equipment has been strengthened in order to control the structures response in dynamic loads such as wind and earthquake. In this research, we dealt with seismic performance of base isolated structures with lead-rubber bearing (LRB) using incremental dynamic analysis (IDA). For this purpose, 3- and 9-story buildings have been utilized in the SAC project undergoing 22 earthquake records which were far-fault. Plotting the fragility curve for various states of design time period and isolator damping of LRB, it is observed that, by increasing damping, the isolator has not been activated in small spectrum acceleration, which shows that the annual exceedance probability is increased in immediate occupancy (IO) performance level and decreased in life safety (LS) performance level. The results show the reduction of determined failure probability in fragility curves for two levels of performance of uninterrupted use and lateral safety. Likewise obtained results show that, with increasing design time period of isolator, the amount of failure probability is decreased rather than the isolator with smaller design time period, for both LS and IO states. And the isolator illustrates better performance.
\end{abstract}

\section{Introduction}

Earthquake as a destructive phenomenon threatens its habitants in most of life areas so that decreasing the earthquake irreparable damage has been the final goal of researchers and earthquake scientists. By passing time and changing the viewpoint of plotting based on force to plotting based on performance, the use of nonlinear analyses has been increased. The design method based on the performance is the new one that has mostly been used in new regulations and instructions [1-5]. In the earth movements, undergoing earthquake, some tensions are created in structures which get the structure elements advanced into the yield and failure [6]. The first step in the seismic improvement of existed structures is their evaluation of seismic vulnerability. In recent years, various methods have been presented to investigate the amount of structures vulnerability, where most of them are based on the qualitative and quantitative analyses of structures. The weaknesses and shortcomings of structures are determined based on the evaluations that are performed on them. The use of appropriate method is necessary for the modification of these weaknesses, doing retrofit, and improvement. In most times, there are some restrictions in choosing the improvement methods in structures which 
influence mainly the selected method [7]. Separating the base is one of the most effective and economical methods to prevent the damage which resulted from the earthquake, which makes released energy of earthquake decreased in structure, without getting damaged. One of the modern methods, in order to evaluate systems seismic performance, is the seismic plan of structures based on the performance that observation of structure behavior forms its base from the initial loading in elastic domain to its entire collapse. The prerequisite of this investigation is the use of dynamic analysis methods that covers whole domain of structure behavior. One of the nonlinear dynamic analysis methods is the incremental nonlinear dynamic analysis (IDA). Liauw et al. [8] investigated the combined effects of vertical and horizontal movements of a real earthquake for base isolated structures on the sliding base with different specification of friction and stiffness. The results showed that the earth's vertical movement significantly affects superstructure response and sliding base displacement. Thus, existence of base isolator is so effective in decreasing the superstructure response. Nowadays, the ability of seismic isolator has been demonstrated as a means to reduce the entered earthquake forces to the structure. Until now, many researches have been conducted to evaluate the performance of seismic isolator systems which are one of the most practical in-active systems in controlling the structures vibrations. Kramer [9] investigated the 3-, 7, and 12-story frames in the case of being without and with isolator (LRB) using the IDA analysis. Then, the effect of (LRB) isolator was separately determined in the reinforced concrete structures using fragility curve under 7 earthquakes near and far-fault. Shakib and Fuladgar [10] examined the effect of earthquake motive triple components over the isolated structures response in base by sliding frictional seismic isolator undergoing three components of El-Centro 1940, Tabas 1978, and Northbridge 1994 earthquakes. The results showed that the earthquakes with three movement components can influence the structure's responses with low-period significantly which have sliding seismic isolator. Furthermore, employing structure under various motives can noticeably undergo the structure response, due to being three components of the earthquake [10]. Finding and classification problems in seismology relate to distinction between natural events which contain mostly tectonic and volcanic earthquakes and artificial events, such as underground nuclear explosions, mine blasts, underwater explosions, and military explosions. Perhaps the most important aspect of the seismic source identification problem is that of finding proper discriminant parameters [11-13].

Zhang and Huo [16] used the fragility functions in order to evaluate the isolation devices effect on freeway bridges in IDA and PSDA methods. They made a comparison between the fragility of $2 \mathrm{D}$ and $3 \mathrm{D}$ models of bridge using OpenSees software. Vasiliadis [17] fulfilled the parametric study of the effect of isolator system period over nonlinear seismic response of three main frames in reinforced concrete building and furthermore, the influence of LRB and FPI was studied on the base isolator system. Finally, the maximum developed displacement and the remained displacement of isolator system were introduced. Seo and $\mathrm{Hu}$ [18] studied the Seismic Response and Performance Evaluation of leadrubber bearing (LRB) isolation systems with superelastic shape memory alloy (SMA) on the CBF Building under NF ground motions. The results of this research were the indicative of significant decrease of remaining displacement in comparison with steel bending bars. $\mathrm{Hu}$ [15] made the comparison between base shears and interstory drifts for steel frames bearing lead-rubber bearing (LRB) isolation systems and for this purpose he used nonlinear time history analyses with NF ground motions. Komur [19] investigated the soft-story behavior in RC structures with conventional base and lead core rubber bearing systems under the various seismic loads. Following that, period of the frame system, story acceleration, interstory drift ration, base shear forces, and distribution of plastic hinges and their damage condition have been assessed. Hu [20] conducted seismic analysis and parametric study of SDOF lead-rubber bearing (LRB) isolation systems with recentering shape memory alloy (SMA) bending bars. The results showed that recentering LRB isolators gets the seismic performance improved in terms of strength, energy dissipation, and recentering effect. Kumar et al. [21] studied the influences of intraearthquake variations investigated on the response of base isolated nuclear structures for ten isolation systems of two periods and five characteristic strengths using OpenSees platform. Sharbatdar et al. [22] evaluated seismic response of isolated structures with lead core rubber bearing and the frictional Pandoli isolator undergoing the earthquake near the fault. They came to conclusion that remarkable displacement and speed pulse can significantly change the results of seismic response of isolated structure in records of near fault. In this paper, the seismic performance of base isolated structures and its effect on the various parameters of structure response were studied using incremental dynamic analysis (IDA). For this purpose, 3- and 9-story steel buildings of SAC project have been used under 22 remote records of fault, being introduced in the FEMA-P695 issue. Lead-rubber isolator has been used to isolate the mentioned buildings. Then, by utilizing the fragility curves, we dealt with the precise estimation of structures failure probability and the effect of isolator existence.

\section{Lead-Rubber Isolators}

The use of isolators with similar performance of horizontal springs decreases the amount of earthquake forces and resonance phenomenon with dominant frequency content through the change in inherent time period of structure. The act of increasing time period of structure is the same concept of using isolators [23]. Seismic isolation is one of the most diverse ways to encounter with earthquake, that by increasing the time period of structure and force transfer interruption path, it helps new structures, even retrofitting available structures [24]. The lead-rubber isolator has been more prevalent among isolator systems and has heavily been used in New Zealand, the United States, and Japan. These isolators contain some layers of steel and rubber plates with 


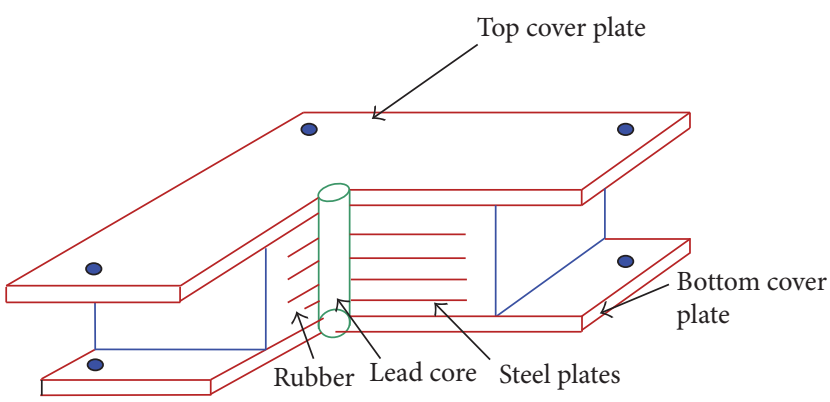

(a)

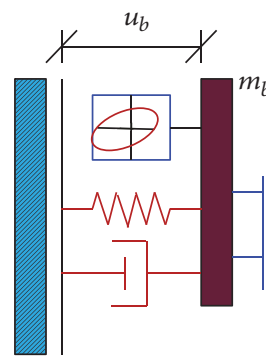

(b)

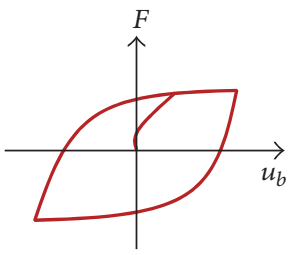

(c)

Figure 1: (a) General form of Rubber isolators with lead core, (b) calculation model, and (c) force-displacement diagram [14].

lead bar which is embedded in some holes. The lead cores deform in about 10 MPA shearing stress and make two lines' response generated in lead. The role of this lead core is energy dissipation and ultimately it gets the amount of isolator displacement declined; thus, it can be called an auxiliary damper [14] that it has been shown in Figure 1.

The first detached building with rubber-lead supports was in New Zealand in 1981. Afterward it was used in other buildings in various countries. Detached buildings with lead supports performed satisfactory performance in Northridge and Kobe earthquake [23].

\section{Incremental Dynamic Analysis Principles}

The method of incremental dynamic analysis (IDA) contains a collection of several dynamic analyses of nonlinear time history of structure where undergoing different severity of earthquakes is incremental. One of the most important subjects in incremental dynamic analysis method is the selection of intensity criterion and suitable damage in which structures are set under one or several seismographs of earthquake record which have been measured in different magnitude levels. After doing the analysis, one or several IDA curves will be made in parametric response against intensity levels. Ultimately by defining Load and Resistance Factor Design states and combining results with risk analysis curves, we dealt with evaluation of structures [25]. So the incremental dynamic analysis method is a multipurpose method with much more usage. The structure's behavior completely depends on the selected record in the IDA curve [26].

\section{Research Methodology and Systems of Studied Structures}

In this study, 3- and 9-story structures [27] have been used for steel project of phase- 2 of SAC. The 3-story structure has 4 spans in north-south direction and 4 spans in westeastern direction, $11.89 \mathrm{~m}$ height, the seismic mass of first and second stories of $9.57 * 10^{5} \mathrm{~kg}$, third story of $1.04 * 10^{6} \mathrm{~kg}$, and total seismic mass of $2.95 * 10^{6} \mathrm{~kg}$. The 9-story structure has 5 spans in both north-south and west-eastern directions, $37.19 \mathrm{~m}$ height, seismic mass of ground floor of $9.65 * 10^{5} \mathrm{~kg}$, first story of $1.01 * 10^{6} \mathrm{~kg}$, and second story to eight story of $9.89 * 10^{5} \mathrm{~kg}$, and total seismic mass above the ground level is $9.10 * 10^{6} \mathrm{~kg}$. The systems of studied structure against the wind force are the steel moment resisting frames which have been shown in Figure 2.

In this study, firstly, base isolated structure with lead core and then fixed base structure has been studied. Afterwards the influence of isolator has been compared over the structure's response under IDA analysis.

4.1. The Isolator Design. In this study, the used isolator system is the rubber isolator with lead core. To design the isolators, the proportion of effective damping $\left(\xi_{\text {eff }}\right)$ for support and design time period $\left(T_{D}\right)$, effective horizontal stiffness $\left(K_{\text {eff }}\right)$, and the maximum horizontal displacement of support $(D)$ have been calculated per shearing strain of design $\left(\gamma_{\max }\right)$. Then according to the design algorithm for seismic isolators LRB [28], it has been dealt with in other isolator specifications. The specification of designed isolator has been presented based on time period for 3- and 9-story structures in Table 1.

According to Table 1, each one of the isolators has been brought for design time periods of $2.5,4$, and 5.5 seconds, per various damping ratios.

4.2. Nonlinear Modeling of Structures. In this study, the OpenSees finite element software has been used to model and to analyze nonlinear dynamic of structures. The OpenSees software has been provided by a research team under Mazzoni supervision in the earthquake engineering and soil dynamic field based on finite element method, in PEER engineering research center at California Berkeley University in 1990 [29]. To modeling beams and columns of structure, the "nonlinearBeamColumn" element (based on distributed plasticity theory) has been used by "Steel 02" material. The analytical spring models (zeroLength element) usually employed for simulating the behavior of LRB devices, are constructed with the OpenSees (Figure 3). In this study, "KikuchiAikenLRB" material [29] which produces nonlinear hysteretic curves of lead-rubber bearings has been assigned to the spring. 


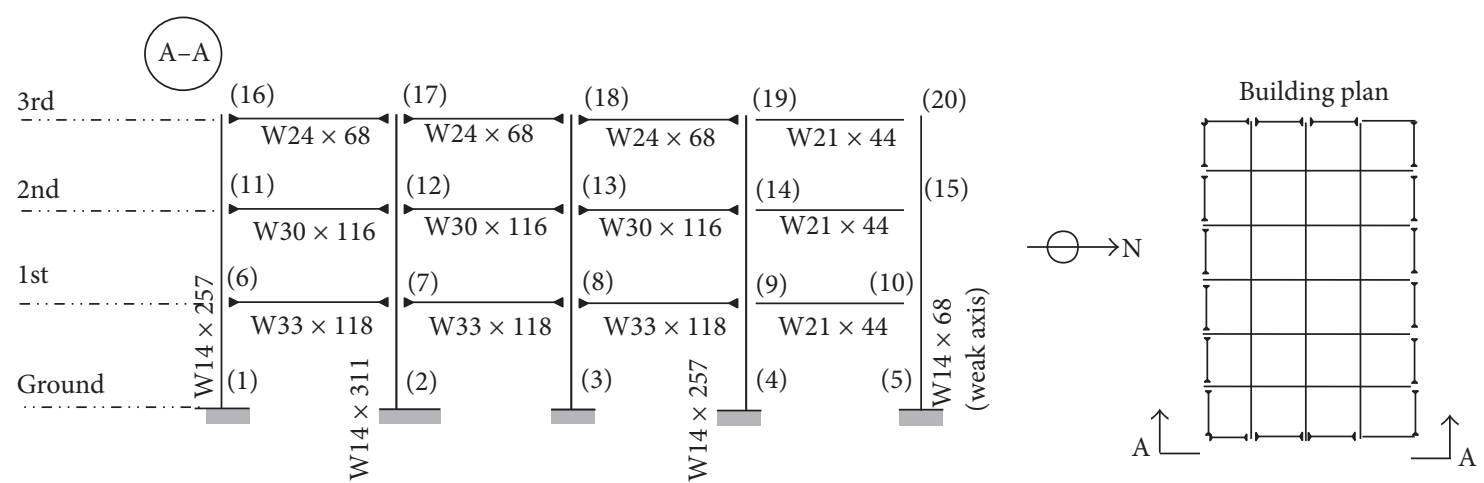

(a)
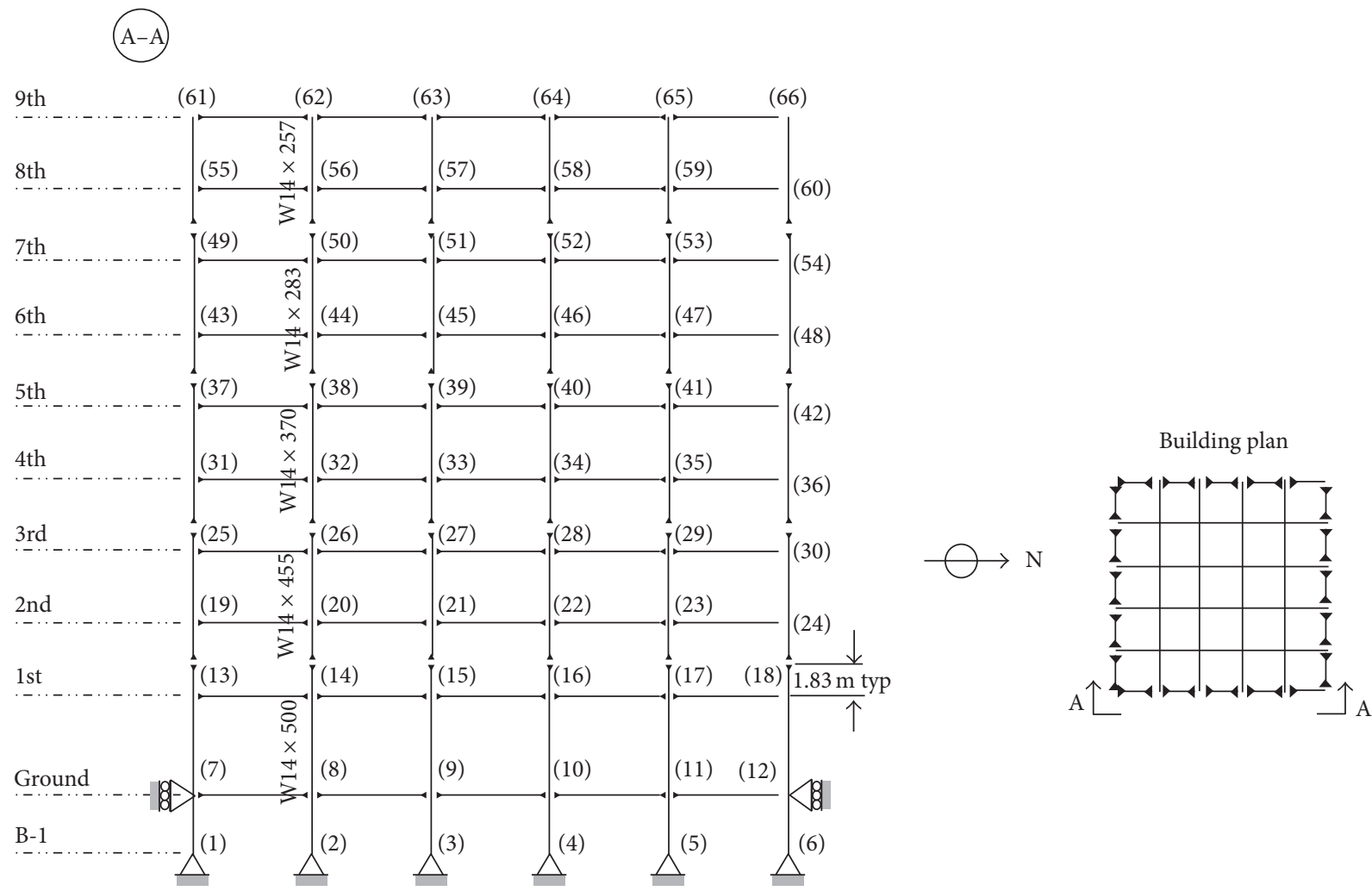

(b)

FIgURE 2: Plan and elevation of selected (a) 3-story building and (b) 9-story building.

Also, in order to control LRB displacement "truss" element was employed at both ends of structure and "ElasticPPGap" material has been assigned (Figure 4).

4.3. Utilized Records in This Study. One of the important issues in incremental dynamic analysis is determining the entered records to the structure. Therefore, suitable numbers of earthquake record should be selected to cover the range of structure response. Regarding study of Shome [30] using 10 to 20 ground motion records usually is enough in order to estimate the damage demand of buildings. In this study, the records of FEEMA P695 have been used for far domains which are 22 ones, in order to fulfill incremental dynamic analyses. The specification of used records has been presented in Table 2.

\section{Results and Discussion}

In this study, firstly the IDA curves of structures have been plotted under 22 records. Then the structures have been assessed under the same records with LRB isolators in the columns base, though the gap material has been used to control the isolator displacement.

Three states have been considered for each structure in isolators design and the analysis of structures for different time period has been dealt with $\left(T_{D}=2.5,4\right.$, and 5.5$)$, by assuming $Q / W=0.03,0.06$, and 0.09 . 
TABLE 1: Design of base isolation $(\xi=$ effective damping ratio, $Q=$ yield force, $W=$ energy dissipated, $A p=$ cross-sectional area of the lead core, and $A 0=$ cross-sectional area of the bearing).

(a) 3-story structure

\begin{tabular}{|c|c|c|c|c|c|c|}
\hline$\xi$ & $T_{D}(\mathrm{sec})$ & $Q / W$ & $K_{\text {eff }}(\mathrm{kN} / \mathrm{m})$ & $D_{D}(\mathrm{~m})$ & $A p\left(\mathrm{~cm}^{2}\right)$ & $A o\left(\mathrm{~cm}^{2}\right)$ \\
\hline 0.1 & 2.5 & 0.03 & 2326.584 & 0.30535 & 135.6375 & 4835.5615 \\
\hline 0.26 & 2.5 & 0.06 & 2326.584 & 0.226185 & 271.35 & 4836.8984 \\
\hline 0.48 & 2.5 & 0.09 & 2326.584 & 0.185061 & 406.9125 & 4835.5615 \\
\hline 0.19 & 4 & 0.03 & 908.8219 & 0.398824 & 135.6375 & 4835.5615 \\
\hline 0.52 & 4 & 0.06 & 908.8219 & 0.293136 & 271.275 & 4835.5615 \\
\hline 0.78 & 4 & 0.09 & 908.8219 & 0.293136 & 406.9125 & 4835.5615 \\
\hline 0.3 & 5.5 & 0.03 & 480.6992 & 0.474191 & 135.6375 & 4835.5615 \\
\hline 0.71 & 5.5 & 0.06 & 480.6992 & 0.403062 & 271.275 & 4835.5615 \\
\hline 1 & 5.5 & 0.09 & 480.6992 & 0.403062 & 406.9125 & 4835.5615 \\
\hline
\end{tabular}

(b) 9-story structure

\begin{tabular}{lcccccc}
\hline$\xi$ & $T_{D}(\mathrm{sec})$ & $Q / W$ & $K_{\text {eff }}(\mathrm{kN} / \mathrm{m})$ & $D_{D}(\mathrm{~m})$ & $A p\left(\mathrm{~cm}^{2}\right)$ & 11803.47594 \\
\hline 0.1 & 2.5 & 0.03 & 5679.1296 & 0.30535 & 331.0875 & 662.175 \\
0.26 & 2.5 & 0.06 & 5679.1296 & 0.2290125 & 0.18506061 & 993.2625 \\
0.48 & 2.5 & 0.09 & 5679.1296 & 0.39882449 & 331.0875 & 11803.47594 \\
0.19 & 4 & 0.03 & 2218.41 & 0.293136 & 662.175 & 11803.47594 \\
0.52 & 4 & 0.06 & 2218.41 & 0.293136 & 993.2625 & 11803.47594 \\
0.78 & 4 & 0.09 & 2218.41 & 0.47419059 & 331.0875 & 11803.47594 \\
0.3 & 5.5 & 0.03 & 1173.373884 & 0.403062 & 662.175 & 11803.47594 \\
0.71 & 5.5 & 0.06 & 1173.373884 & 0.403062 & 993.2625 & 11803.47594 \\
1 & 5.5 & 0.09 & 1173.373884 & & 11803.47594 \\
\hline
\end{tabular}

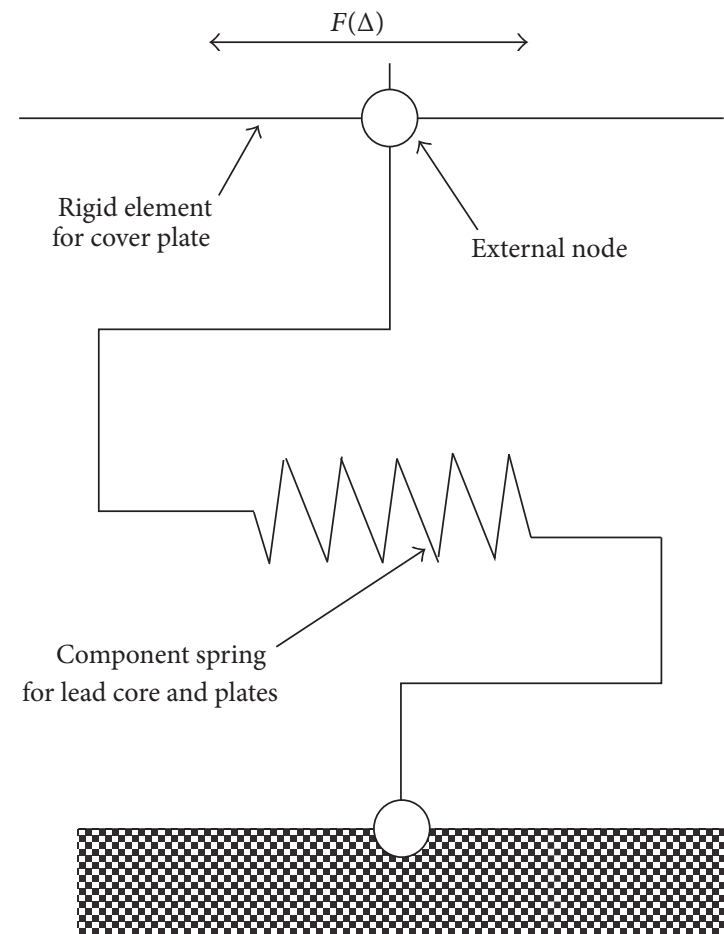

FIGURE 3: Analytical model for component spring (LRB model) [15]. 


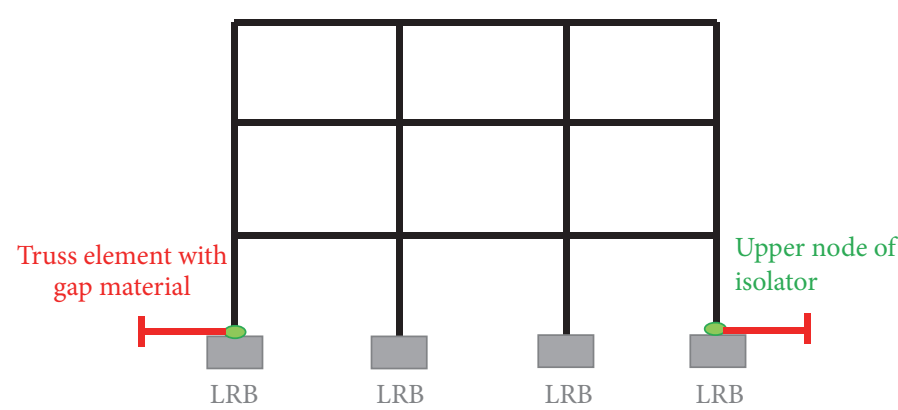

FIGURE 4: Physical model for control of LRB displacement.

TABLE 2: Ground motion database.

\begin{tabular}{|c|c|c|c|c|}
\hline \multirow{2}{*}{$\begin{array}{l}\text { ID } \\
\text { Number }\end{array}$} & \multicolumn{3}{|c|}{ Earthquake } & \multirow{2}{*}{$\begin{array}{c}\text { Recording station } \\
\text { Name }\end{array}$} \\
\hline & M & Year & Name & \\
\hline 1 & 6.7 & 1994 & Northridge & Beverly Hills-Mulhol \\
\hline 2 & 6.7 & 1994 & Northridge & Canyon Country-WLS \\
\hline 3 & 7.1 & 1999 & Duzce, Turkey & Bolu \\
\hline 4 & 7.1 & 1999 & Hector Mine & Hector \\
\hline 5 & 6.5 & 1979 & Imperial Valley & Delta \\
\hline 6 & 6.5 & 1979 & Imperial Valley & El Centro Array \#11 \\
\hline 7 & 6.9 & 1995 & Kobe, Japan & Nishi-Akashi \\
\hline 8 & 6.9 & 1995 & Kobe, Japan & Shin-Osaka \\
\hline 9 & 7.5 & 1999 & Kocaell, Turkey & Duzce \\
\hline 10 & 7.5 & 1999 & Kocaell, Turkey & Arcellk \\
\hline 11 & 7.3 & 1992 & Landers & Yermo Fire Station \\
\hline 12 & 7.3 & 1992 & Landers & Coolwater \\
\hline 13 & 6.9 & 1989 & Loma Prieta & Capltola \\
\hline 14 & 6.9 & 1989 & Loma Prieta & Gllory Array \#3 \\
\hline 15 & 7.4 & 1990 & Manjil, Iran & Abbar \\
\hline 16 & 6.5 & 1987 & Superstition Hills & El Centro Imp. Co. \\
\hline 17 & 6.5 & 1987 & Superstition Hills & Poe Road (temp) \\
\hline 18 & 7.0 & 1992 & Cape Mendocino & Rio Dell Overpass \\
\hline 19 & 7.6 & 1999 & Chi-Chi, Taiwan & CHY101 \\
\hline 20 & 7.6 & 1999 & Chi-Chi, Taiwan & TCU045 \\
\hline 21 & 6.6 & 1971 & San Fernando & LA-Hollywood Stor \\
\hline 22 & 6.5 & 1976 & Friuli, Italy & Tolmezzo \\
\hline
\end{tabular}

\subsection{The IDA Analysis Curves of Studied Structures}

5.1.1. The IDA Analysis Curves of 3-Story Structure. According to Figure 5, 3-story structure in 3 states has been dealt with.

First state: design time period of 2.5 seconds' isolator $Q / W=0.03$ and $10 \%, 26 \%$, and $48 \%$ damping

Second state: design time period of 4 seconds' isolator $\mathrm{Q} / W=0.06$ and $19 \%, 52 \%$, and 78\% damping

Third state: design time period of 5.5 seconds' isolator $Q / W=0.09$ and $30 \%, 71 \%$, and $100 \%$ damping

According to Figure 5, it is observed that used elements have no stiffness to control the displacement of seismic isolator with gap material, just before the displacement of isolator design and as the isolator reaches design displacement; it gets the element hardened and transfers the acceleration to the structure, in order to use the capacity of structure too and it will have less relative displacements than the fixed base structure. On the other hand, when the structure is isolated, IDA analysis curve of base isolated structure has more primary slope than the fixed base structure, indicating the reduction of relative displacement.

Furthermore, it is seen that, by increasing damping percentage, the relative displacement amount of structure-in constant amount of $\mathrm{Sa}$-is declined and the relative displacement amount of isolated structure-with each damping ratio-is less than the structure without isolator. 

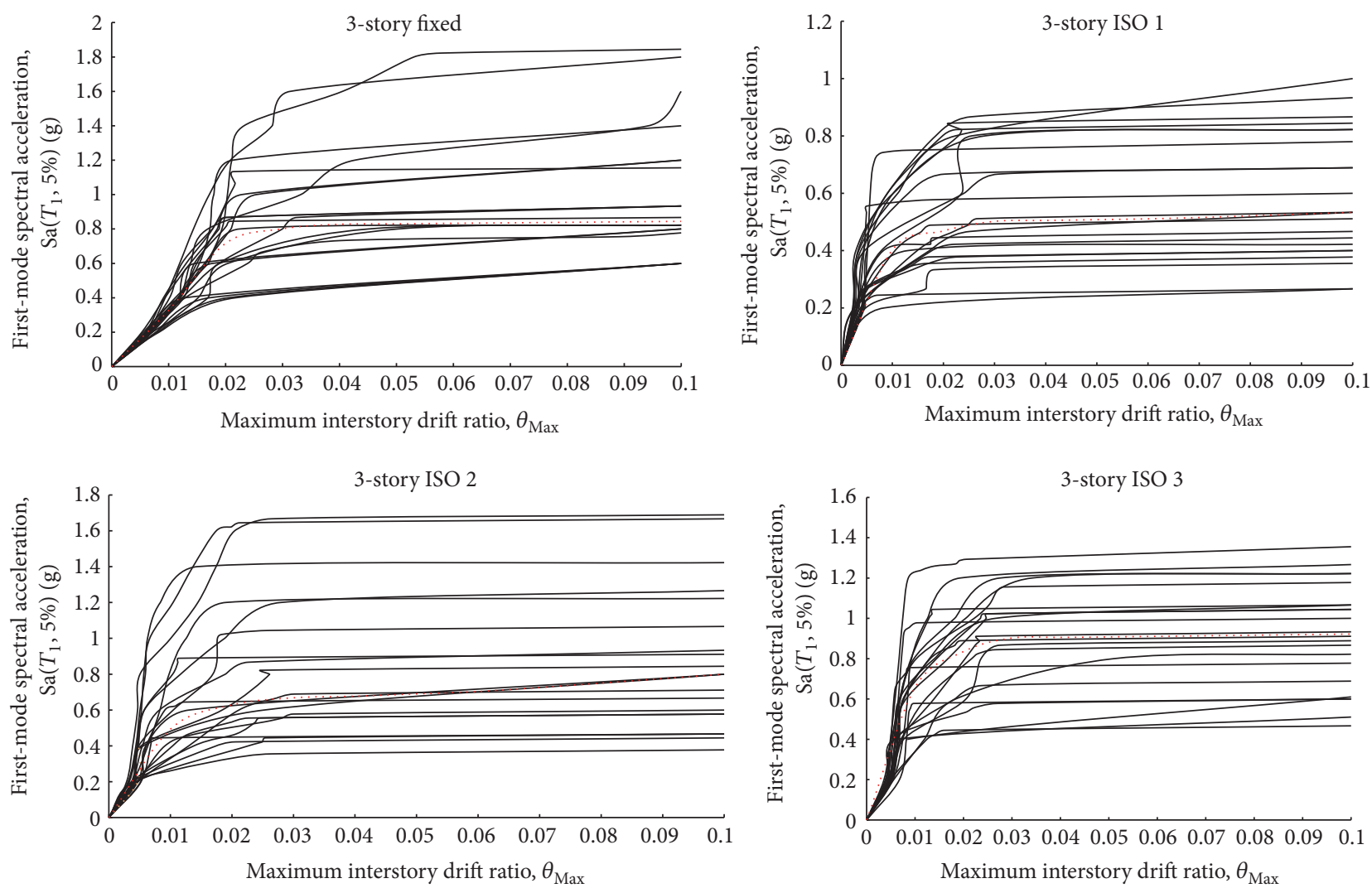
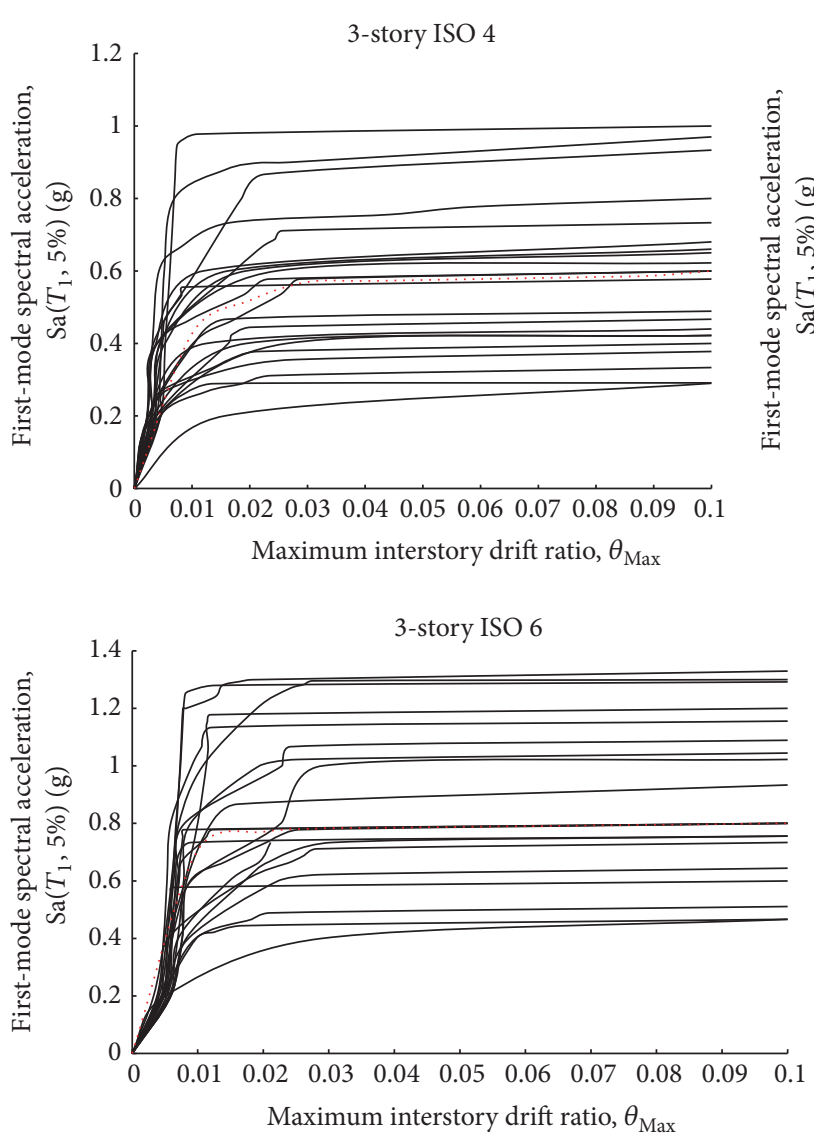

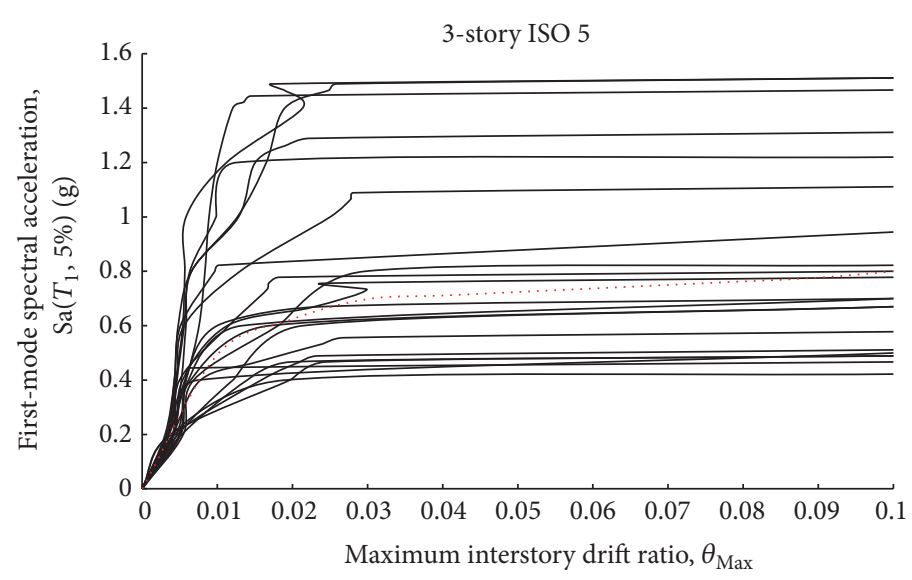

3-story ISO 7

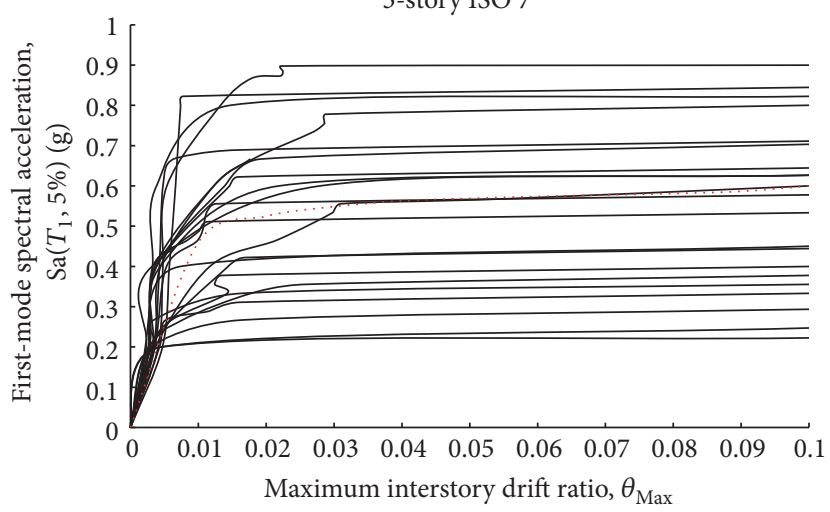

Figure 5: Continued. 

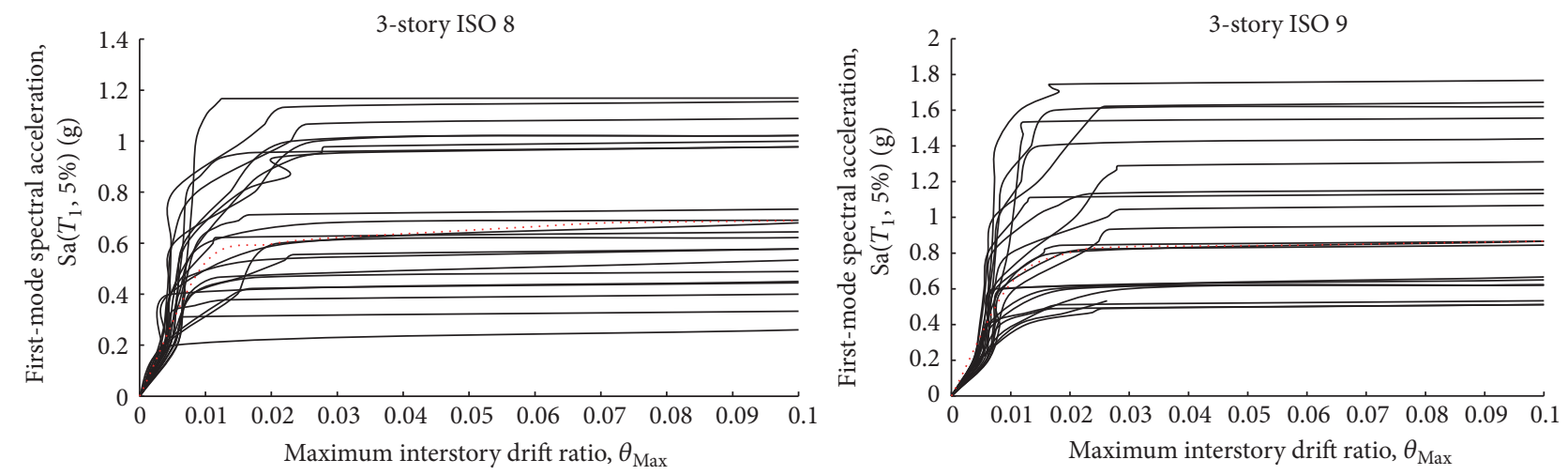

Figure 5: IDA curves for 3-story frame (ISO 1 to 9 are related to damping ratios $0.1,0.26,0.48,0.19,0.52,0.78,0.3,0.71$, and 1.0 , resp.).

5.1.2. The IDA Analysis Curves of 9-Story Structure. Figure 6 shows the evaluation of incremental dynamic analysis graphs in 9-story structure under 9 isolated states.

As it is observed in Figure 6, in IDA curves category of 9story structure has more primary slope, like 3-story structure; thus, it transfers less relative displacement to the structure.

It should be mentioned that for both 3- and 9-story structures the maximum interstory drift has occurred at bottom stories which indicates the shear behavior (shear building) of structures.

\subsection{Clustering IDA Curves for Various Designs Time Periods}

5.2.1. Clustering IDA Curves for 3-Story Structure. IDA curves for 3-story structure for various design time periods have been presented in Figure 7.

In Figure 7, it is observed that the base isolated structure-in constant amount of $\mathrm{Sa}$-has less relative displacement. Also being abounded the primary slope of diagram with more damping amount gets the relative displacement to be decreased. The time period and spectral acceleration of 3-story structure have been presented in two levels of performance, in Figure 5.

In Table 3 the amounts of annual exceedance probability have been presented for 3-story structure.

As it is observed in Figure 5, by adding LRB isolator, the time period of 3-story structure is increased rather than state of constant base, though by increasing damping, time period has a descending procedure. For example, in the isolator with design time period of 2.5 seconds, it has $2.11,1.5$, and 1.37 seconds' time period of structure, per $10 \%, 26 \%$, and $48 \%$ damping, respectively.

Likewise it can be concluded that, by raising damping in structure, the intensity magnitude with immediate occupancy performance levels and lateral safety is increased and by raising time period of designed isolator, these quantities are declined.

5.2.2. Clustering IDA Curves for 9-Story Structure. IDA curves for 9-story structure have been presented in Figure 8 for various designs time periods.
In Figure 8, as it is observed, base isolated structure has more primary slope in various design time periods than fixed base structure that make the stories relative displacement decrease. Existing chaos is because of various behaviors of tall structures rather than vibrational modes and sensibility to the entered records of earthquake. But isolator also has ideal effect in structure. For instance, the isolator in $26 \%$ damping has demonstrated better effect from itself than $48 \%$ damping. Furthermore, in the second cluster curves, 52\% damping and in the third cluster curves $71 \%$ damping have the most reduction in relative displacement of stories.

5.3. Hazard Spectrum. To investigate the structure, the amount of spectral acceleration should be extracted from the related response spectrum in various levels of performance. In Figure 9 the hazard spectrum has been shown for two levels of IO performance, equivalent to spectrum DBE of AISC code and for performance level of LS from MCE spectrum.

5.4. Fragility Curve. For quantitative expression of structural and nonstructural various components vulnerability, the exceedance probability can be expressed from a special amount of damage based on a reference characteristic of earthquake such as PGA, PGD, and PGV, according to the amount of earthquake risk. Repetition of this operation for various amounts of PGA (or other parameters) gets the normal curves to be produced, which are prevalent as the fragility curve. These curves consider uncertainties, related changes to the capacity curve characteristic, failure states, and earth motion.

A fragility curve can be usually produced with the use of a mathematical function related to seismic capacity and demand of the structure, accounting for their uncertainties [31]. Mathematical function of fragility curves can be represented as follows [31]:

$$
P_{f}=\emptyset\left[\frac{\ln \left(S_{d} / S_{c}\right)}{\sqrt{\beta_{d}^{2}+\beta_{c}^{2}}}\right]
$$

in which $P_{f}$ is the conditional probability of exceeding a certain performance limit state; $S_{d}$ is the seismic demand 

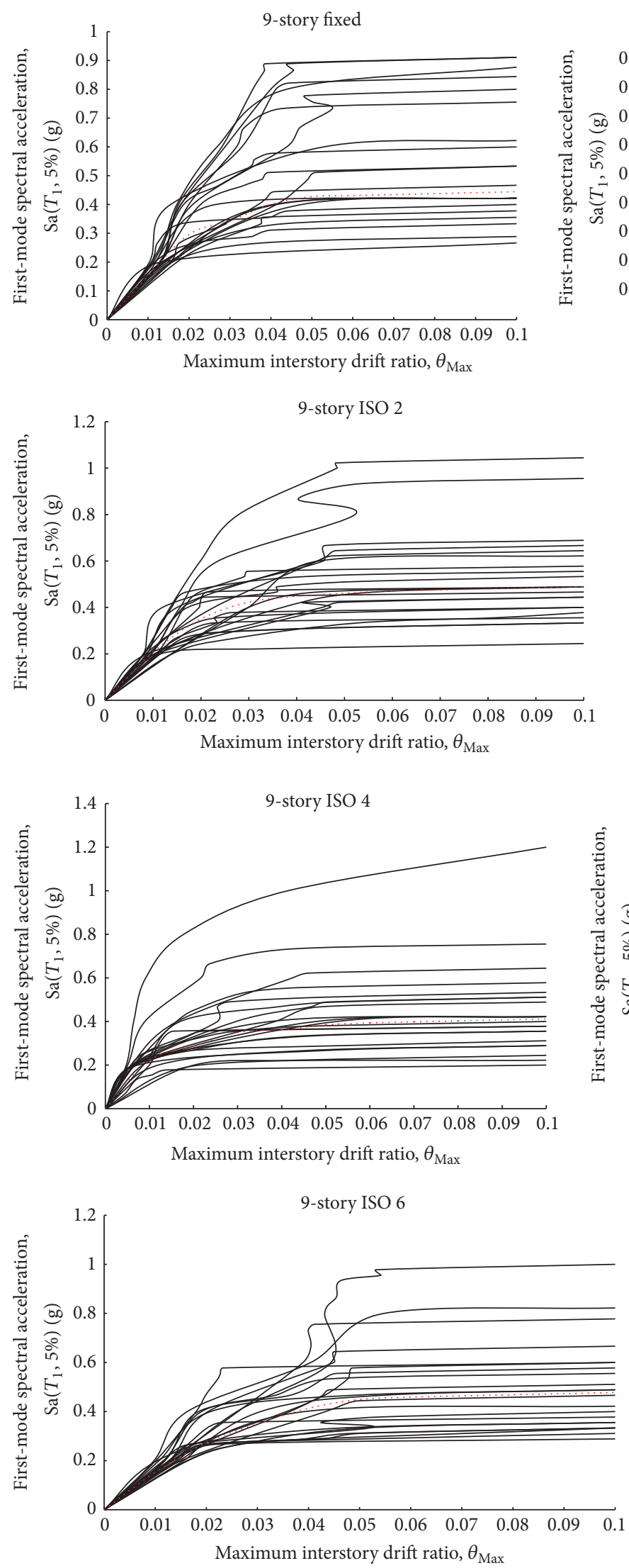
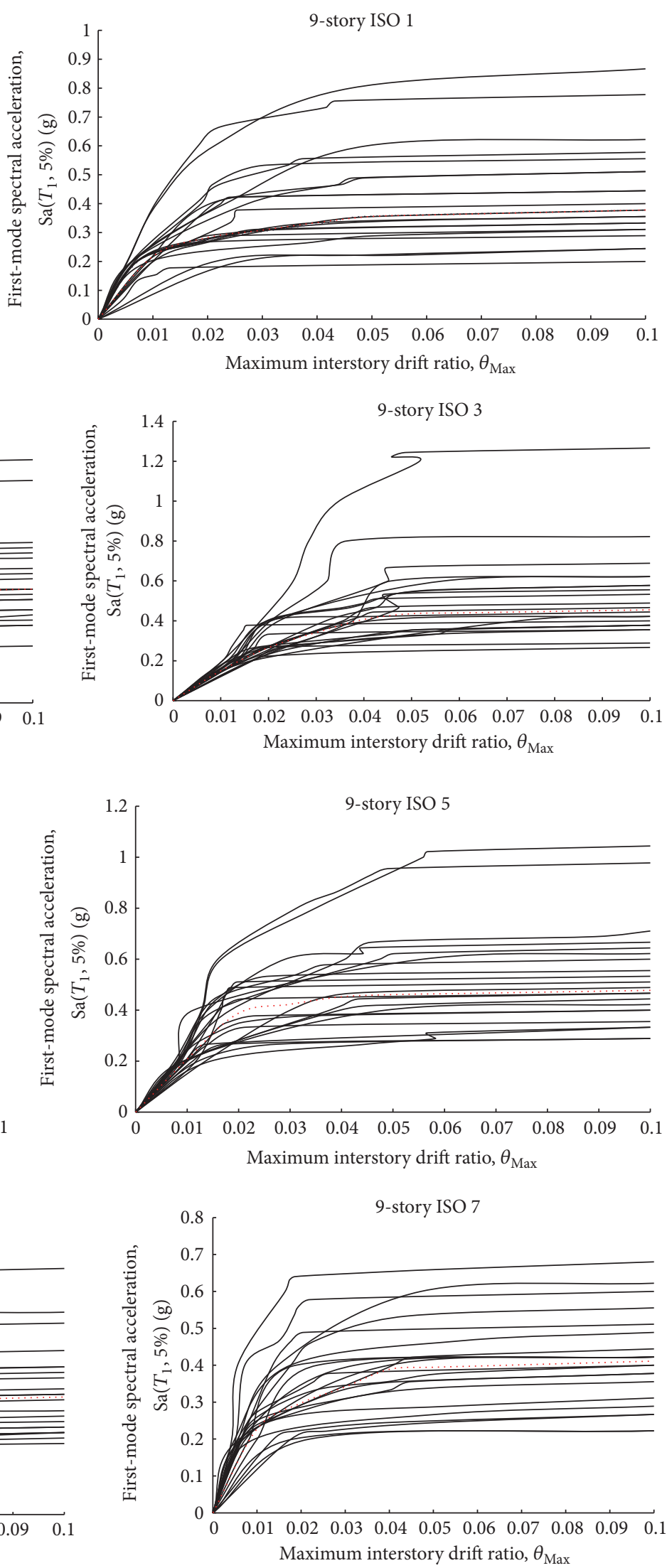

Figure 6: Continued. 

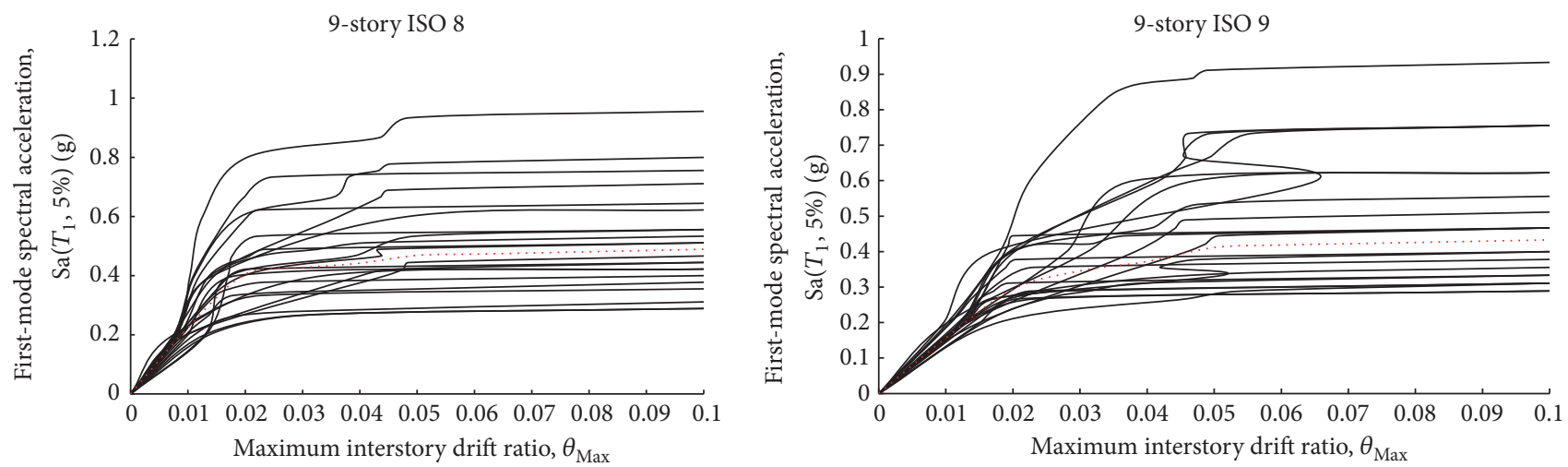

FIGURE 6: IDA curves for 9-story frame (ISO 1 to 9 are related to damping ratios $0.1,0.26,0.48,0.19,0.52,0.78,0.3,0.71$, and 1.0 , resp.).
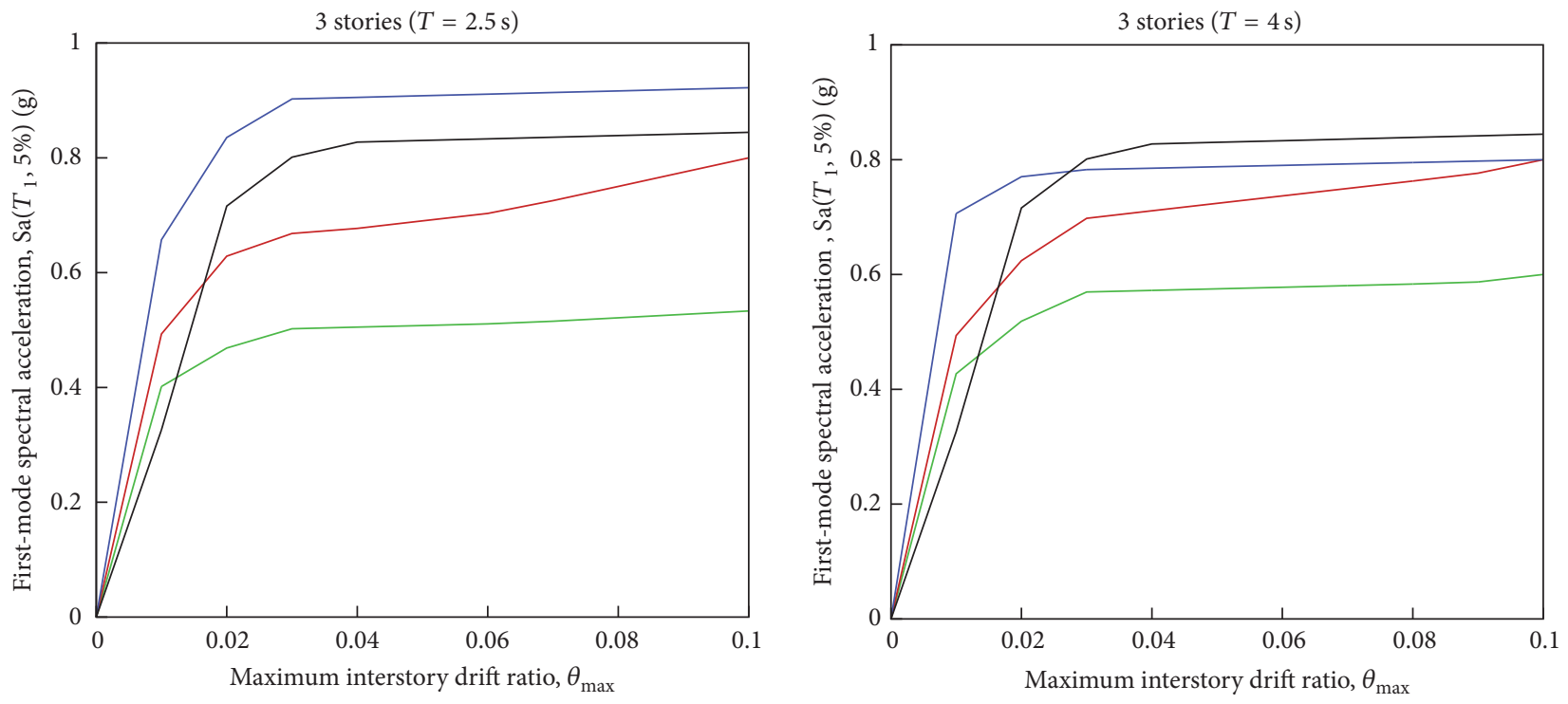

$\begin{array}{llll}-10 \% & -48 \% & -19 \% & -78 \% \\ -26 \% & - \text { Fixed } & -52 \% & \text { Fixed }\end{array}$

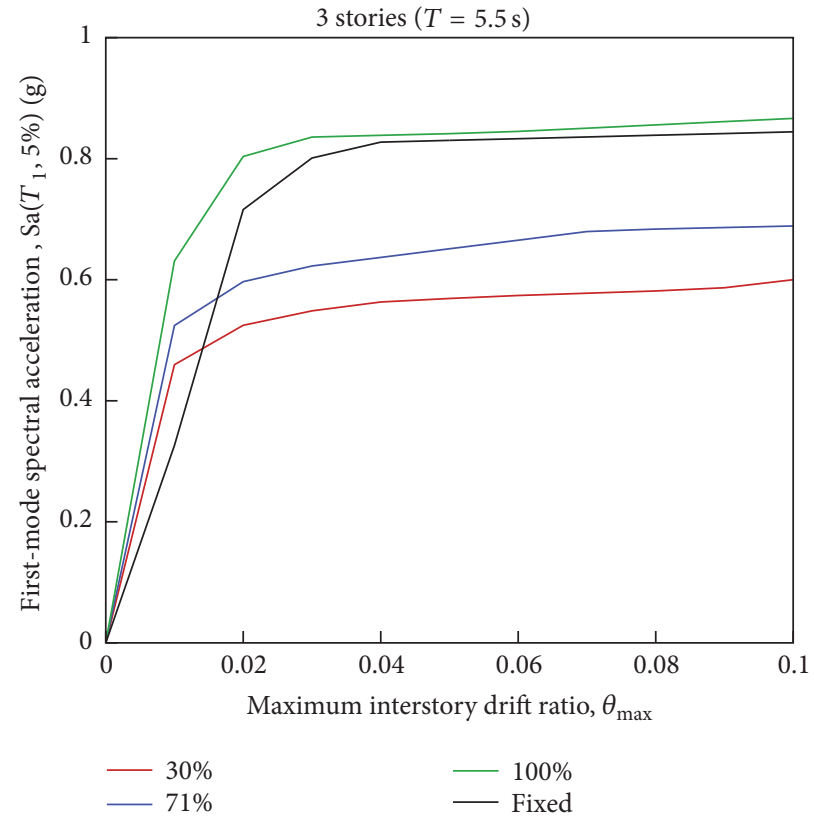

FIGURE 7: Summarized IDA curves for 3-story frame. 
TABLE 3: Periods and spectral accelerations of 3-story frame at IO and LS states.

(a) Period $=2.5 \mathrm{~s}$

\begin{tabular}{lcccc}
\hline Structure & Fixed base & $\begin{array}{c}\text { Base } \\
\text { isolated 1 } \\
(2.5 \mathrm{~s})\end{array}$ & $\begin{array}{c}\text { Base } \\
\text { isolated 2 } \\
(2.5 \mathrm{~s})\end{array}$ & $\begin{array}{c}\text { Base } \\
\text { isolated 3 } \\
(2.5 \mathrm{~s})\end{array}$ \\
\hline Period(s) & 1 & 2.11 & 1.5 & 1.37 \\
$\mathrm{Sa}(\mathrm{IO}(\mathrm{g}))$ & 0.59 & 0.30 & 0.39 & 0.43 \\
$\mathrm{Sa}(\mathrm{LS}(\mathrm{g}))$ & 0.89 & 0.44 & 0.59 & 0.65 \\
\hline
\end{tabular}

(b) Period $=4 \mathrm{~s}$

\begin{tabular}{lcccc}
\hline Structure & Fixed base & $\begin{array}{c}\text { Base } \\
\text { isolated 1 } \\
(4 \mathrm{~s})\end{array}$ & $\begin{array}{c}\text { Base } \\
\text { isolated 2 } \\
(4 \mathrm{~s})\end{array}$ & $\begin{array}{c}\text { Base } \\
\text { isolated 3 } \\
(4 \mathrm{~s})\end{array}$ \\
\hline Period(s) & 1 & 2.35 & 1.72 & 1.54 \\
$\mathrm{Sa}(\mathrm{IO}(\mathrm{g}))$ & 0.59 & 0.25 & 0.34 & 0.38 \\
$\mathrm{Sa}(\mathrm{LS}(\mathrm{g}))$ & 0.89 & 0.38 & 0.52 & 0.58 \\
\hline
\end{tabular}

(c) Period $=5.5 \mathrm{~s}$

\begin{tabular}{lcccc}
\hline Structure & Fixed base & $\begin{array}{c}\text { Base } \\
\text { isolated } 1 \\
(5.5 \mathrm{~s})\end{array}$ & $\begin{array}{c}\text { Base } \\
\text { isolated 2 } \\
(5.5 \mathrm{~s})\end{array}$ & $\begin{array}{c}\text { Base } \\
\text { isolated 3 } \\
(5.5 \mathrm{~s})\end{array}$ \\
\hline Period(s) & 1 & 2.52 & 1.93 & 1.71 \\
$\mathrm{Sa}(\mathrm{IO}(\mathrm{g}))$ & 0.59 & 0.23 & 0.31 & 0.35 \\
$\mathrm{Sa}(\mathrm{LS}(\mathrm{g}))$ & 0.89 & 0.35 & 0.46 & 0.52 \\
\hline
\end{tabular}

caused due to seismic loads; $S_{c}$ is the median value of structural capacity for predefined damage state; $\beta_{d}$ is the logarithmic standard deviation of the demand; $\beta_{c}$ is the logarithmic standard deviation for the capacity; and $\emptyset[]$ is the standard normal distribution function. The parameter $\beta_{c}$ was assumed to be 0.3 following the recommendations from HAZUS [31], while $\beta_{d}$ was computed as the logarithmic standard deviation of seismic responses gained for each floor of the studied structure from the nonlinearly dynamic analyses. As aforementioned, the maximum interstory drift ratios have been widely and efficiently used to generate fragility curves for multistory framing structures at predescribed FEMA different performance levels.

Following that it has been dealt with fragility curves to obtain the vulnerability amount of 3- and 9-story structures.

5.4.1. Fragility Curves for 3-Story Structure. In Figure 10 fragility curves have been shown for 3-story structure.

As can be seen from Figure 10, for the 3-story structure, in base isolated case, the amounts of annual exceedance probability reach together LS and IO performance levels. And in fixed base structure state, these amounts have more distance with each other. By increasing damping in curves with equal design time period, the difference of annual exceedance probability increases in two levels of performance where this difference is so less than fixed base structure. The reason of this significant difference is the reduction of isolator effect in performance level of life safety that decreases the
TABLE 4: Values of annual exceedance probability for 3-story frame.

(a) Period $=2.5 \mathrm{~s}$

\begin{tabular}{lcccc}
\hline Structure & Fixed base & $\begin{array}{c}\text { Base } \\
\text { isolated 1 } \\
(2.5 \mathrm{~s})\end{array}$ & $\begin{array}{c}\text { Base } \\
\text { isolated 2 } \\
(2.5 \mathrm{~s})\end{array}$ & $\begin{array}{c}\text { Base } \\
\text { isolated 3 } \\
(2.5 \mathrm{~s})\end{array}$ \\
\hline Period(s) & 1 & 2.11 & 1.5 & 1.37 \\
Prob(IO) & $100 \%$ & $35 \%$ & $40 \%$ & $45 \%$ \\
Prob(LS) & $68 \%$ & $35 \%$ & $32 \%$ & $26 \%$ \\
\hline
\end{tabular}

(b) Period $=4 \mathrm{~s}$

\begin{tabular}{lcccc}
\hline Structure & Fixed base & $\begin{array}{c}\text { Base } \\
\text { isolated 1 } \\
(4 \mathrm{~s})\end{array}$ & $\begin{array}{c}\text { Base } \\
\text { isolated 2 } \\
(4 \mathrm{~s})\end{array}$ & $\begin{array}{c}\text { Base } \\
\text { isolated 3 } \\
(4 \mathrm{~s})\end{array}$ \\
\hline Period(s) & 1 & 2.11 & 1.5 & 1.37 \\
Prob(IO) & $100 \%$ & $24 \%$ & $26 \%$ & $28 \%$ \\
Prob(LS) & $68 \%$ & $23 \%$ & $22 \%$ & $17 \%$ \\
\hline
\end{tabular}

(c) Period $=5.5 \mathrm{~s}$

\begin{tabular}{lcccc}
\hline Structure & Fixed base & $\begin{array}{c}\text { Base } \\
\text { isolated 1 } \\
(5.5 \mathrm{~s})\end{array}$ & $\begin{array}{c}\text { Base } \\
\text { isolated 2 } \\
(5.5 \mathrm{~s})\end{array}$ & $\begin{array}{c}\text { Base } \\
\text { isolated 3 } \\
(5.5 \mathrm{~s})\end{array}$ \\
\hline Period(s) & 1 & 2.11 & 1.5 & 1.37 \\
Prob(IO) & $100 \%$ & $10 \%$ & $18 \%$ & $24 \%$ \\
Prob(LS) & $68 \%$ & $22 \%$ & $21 \%$ & $13 \%$ \\
\hline
\end{tabular}

amount of damage remarkably, whilst the isolator shows less proficiency from itself in the level of immediate occupancy. In Table 4 the amount of annual exceedance probability in 3story structure has been presented.

The exceedance probability for two levels of performance in 3-story structure is as follows.

In Figure 11 the exceedance probability for two levels of performance has been illustrated for 3-story structure.

Comparison of the amounts of exceedance probability for 3-story structure in Figure 11 shows that, by increasing damping, the annual exceedance probability in immediate occupancy level performance is increased and is decreased in life safety performance level and that this amount is less than constant structure. The isolator in immediate occupancy performance has appropriate proficiency but by increasing damping, the amounts of exceedance probability are increased. In other words, the isolator shows better proficiency from itself in low damping and it is opposite the state which happens in life safety. Likewise by increasing design time period (for example, 5.5 seconds) the amounts of failure probability are decreased and the isolator shows better performance

5.4.2. Fragility Curves of 9-Story Structures. In Figure 12 fragility curves have been shown for 9-story structure.

In Table 5 the amounts of annual exceedance probability have been presented for 9-story structure.

The exceedance probability in two levels of performance in 9-story structure is as follows. 

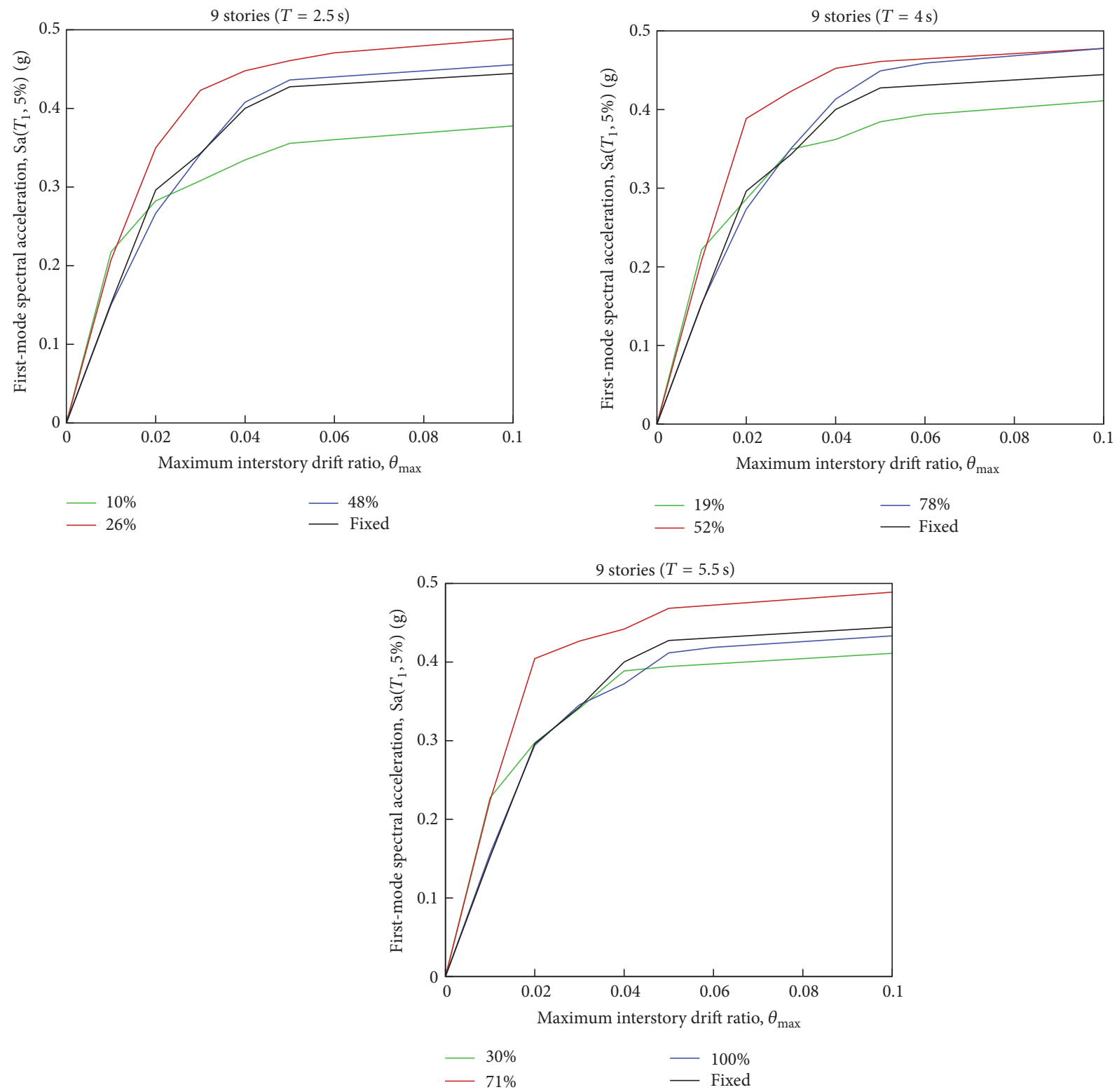

FIGURE 8: Summarized IDA curves for 9-story frame.

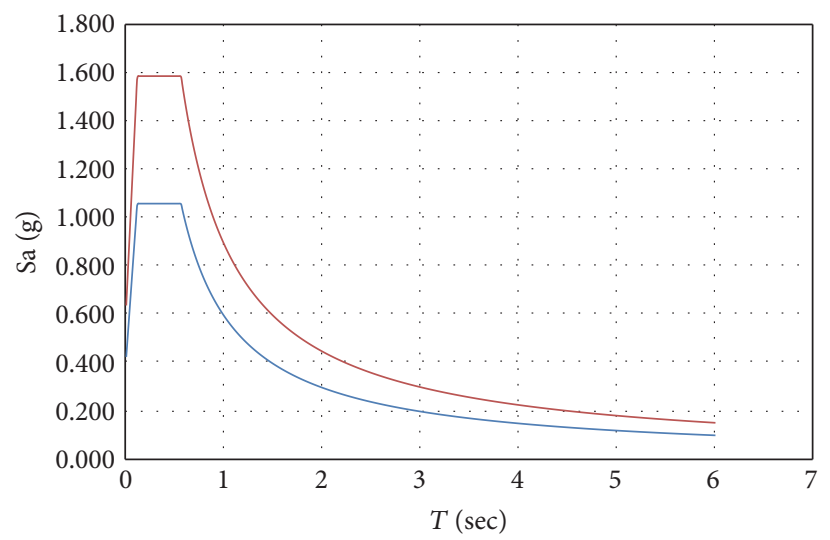

- DBE (IO)

- mce (ls)

FIGURE 9: Simplified hazard spectrum. 

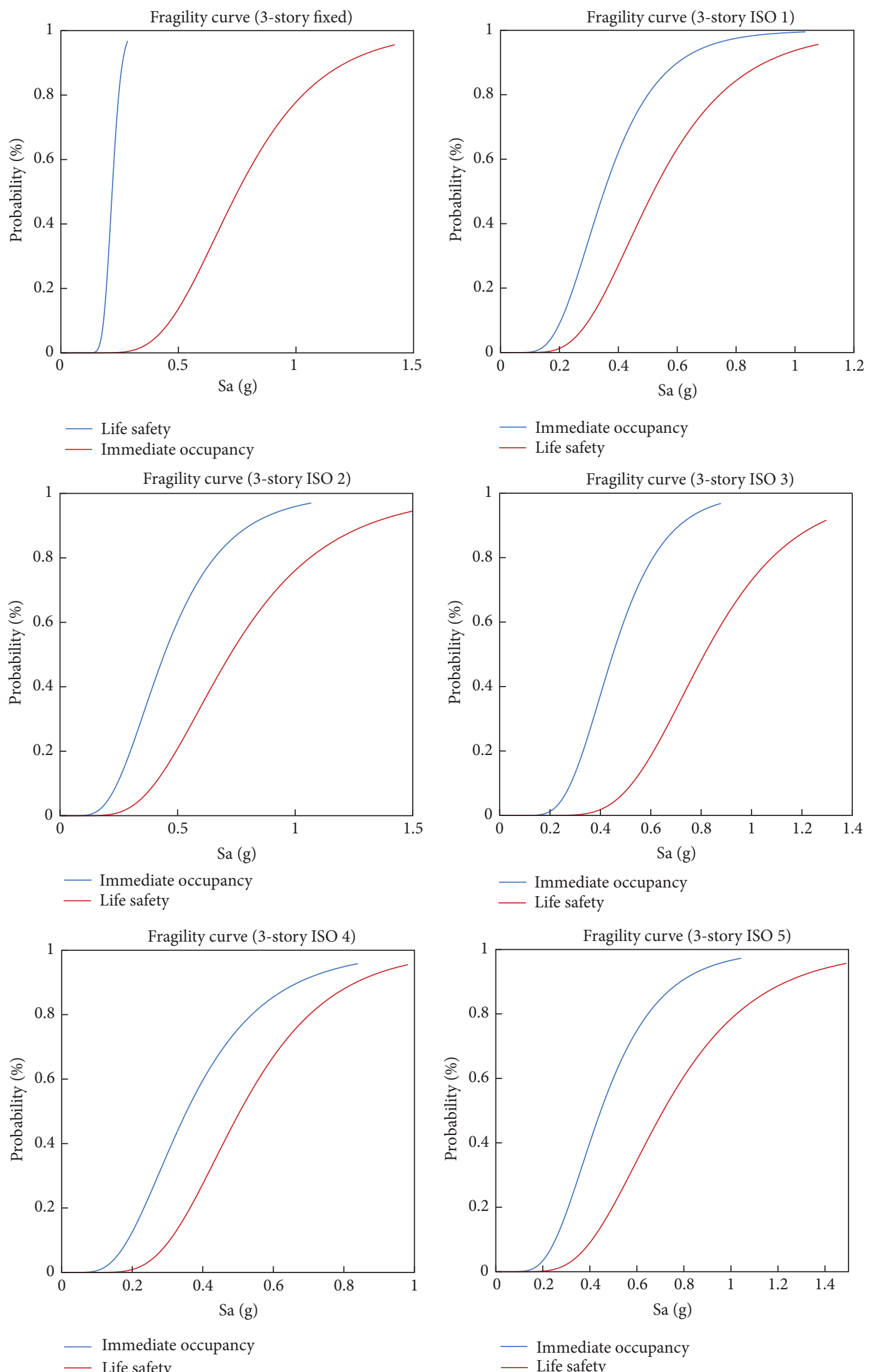

Figure 10: Continued. 

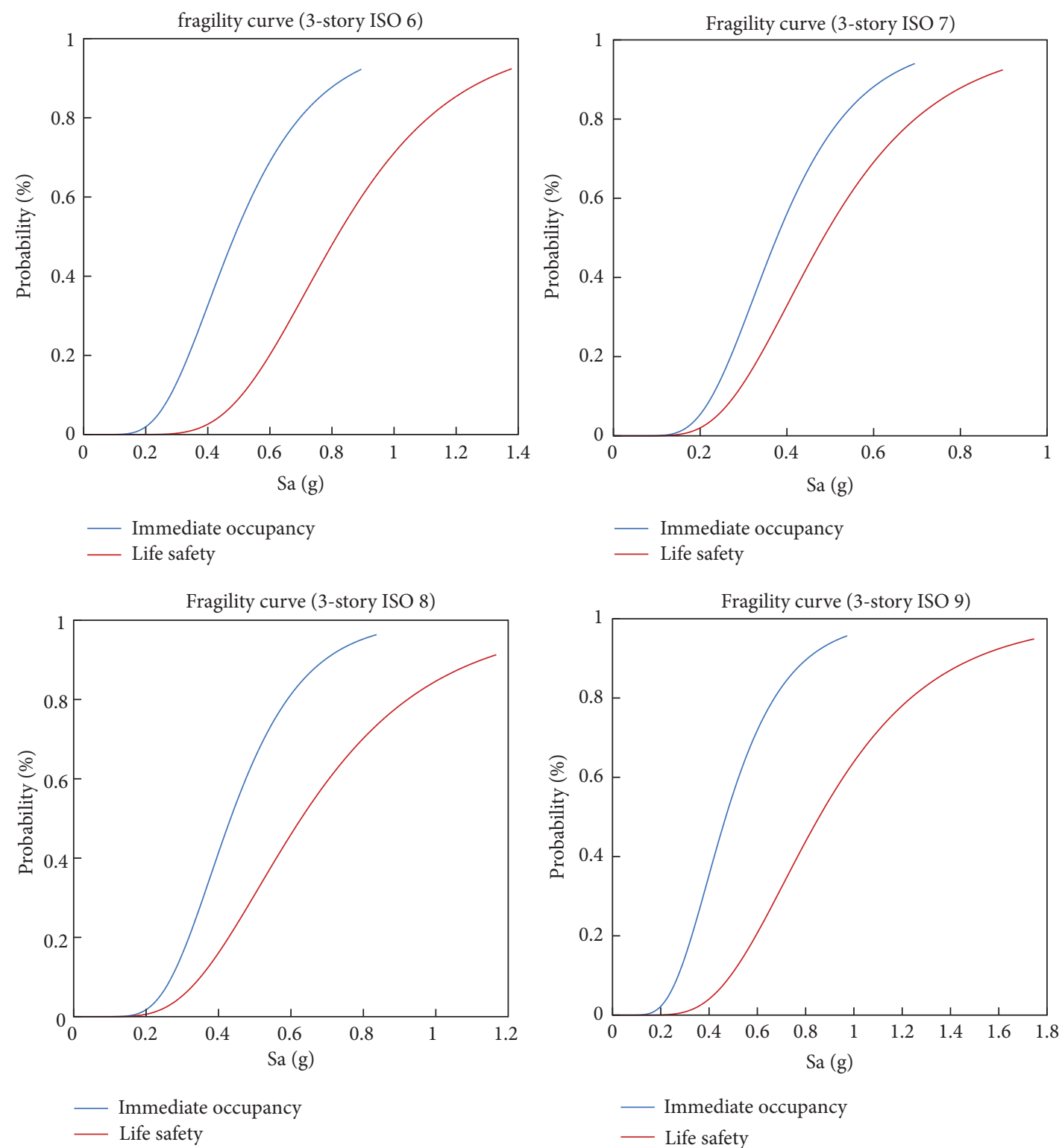

FIGURE 10: Fragility curves of 3 -story frame (ISO 1 to 9 are related to damping ratios $0.1,0.26,0.48,0.19,0.52,0.78,0.3,0.71$, and 1.0 , resp.).

In Figure 13 the exceedance probability has been illustrated in two levels of performance for 9-story structure.

According to Figure 13, it is observed that, by increasing damping, like 3-story structure, the annual exceedance probability in immediate occupancy level performance is increased and it is declined in life safety performance where, in both states, it is less than constant structure.

In 3- and 9-story structure, increasing damping gets the exceedance probability to be increased in immediate occupancy level performance. Furthermore, the amounts of failure probability reduction are less in 9-story structure; in immediate occupancy level performance, it means the isolator has great proficiency in 3-story structure. For example, the exceedance probability is $26 \%$ in 3 -story structure and $22 \%$ in 9-story structure, in design time period of 2.5 seconds. Therefore, the isolator has proper proficiency in immediate occupancy performance level for 3-story structure and in life safety performance for 9-story structure.

\section{Conclusions}

In this research, we dealt with the seismic performance of base isolated structures and its effect on the various parameters of structure response using incremental dynamic analysis (IDA). For this purpose, 3- and 9-story model of steel buildings of SAC project has been used under 22 remote records of fault, introduced in the FEMA-P695 issue.

(i) It is seen that, in the constant amount of Sa, by increasing damping percentage, the amounts of structures drift decrease. Moreover, the amount of this 

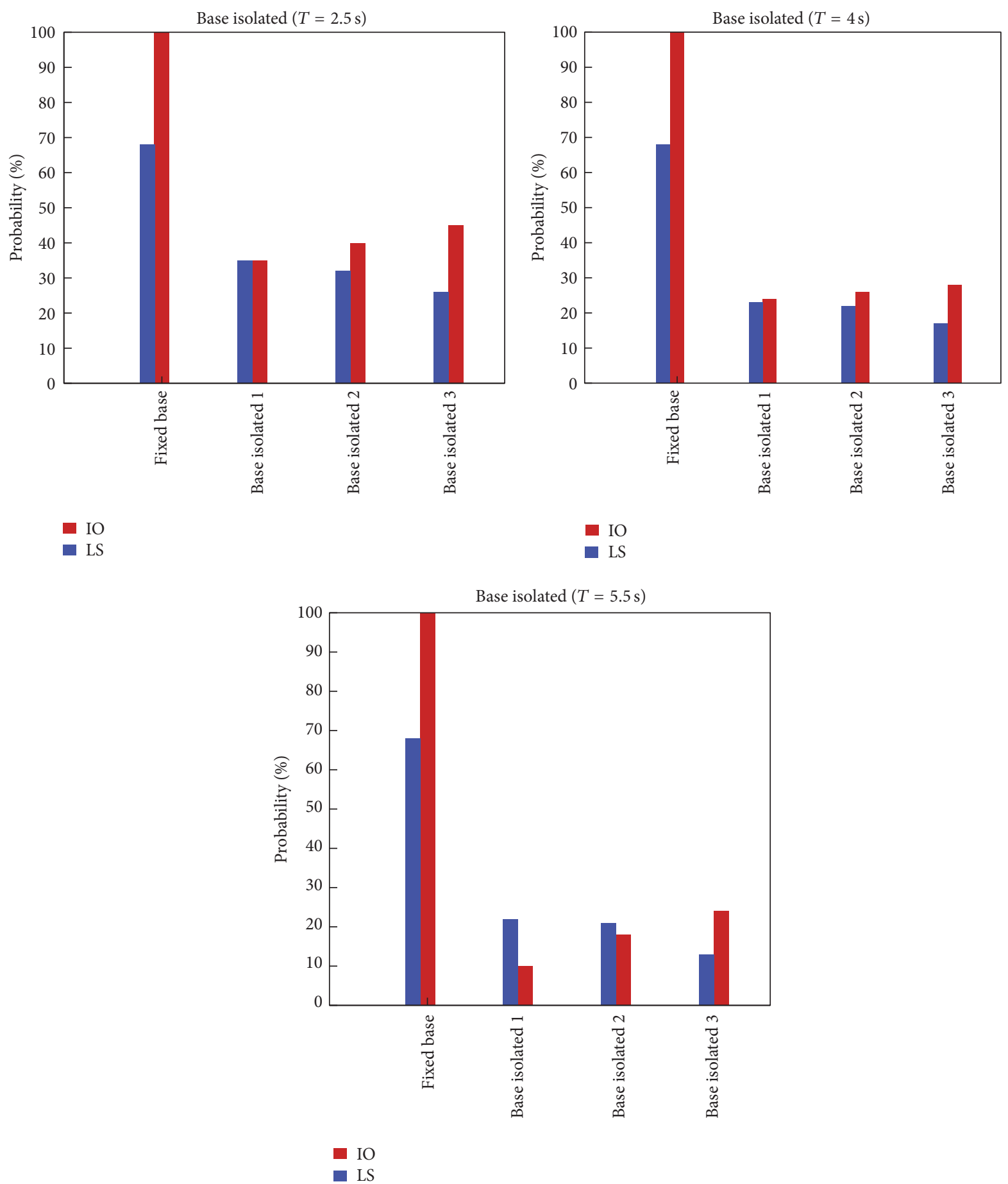

FIGURE 11: Annual exceedance probability of 3-story frame at IO and LS levels.

parameter in base isolated structures is less than fixed base structure in any damping proportion.

(ii) The primary slope of IDA curves in base isolated structures is more than fixed base structure where this procedure indicates the drift reduction.

(iii) Base isolated structure has lower damage probability in comparison with fixed base structure in the specific performance level. In other words, use of isolator gets the performance level of structure improved. By increasing the isolator damping, isolator does not work in the low Sa, because of increase in the lead core diameter, and by raising the isolator damping, this procedure makes the exceedance probability of IO performance level increased, that is equivalent to $0.7 \%$ relative displacement. But when the isolator 

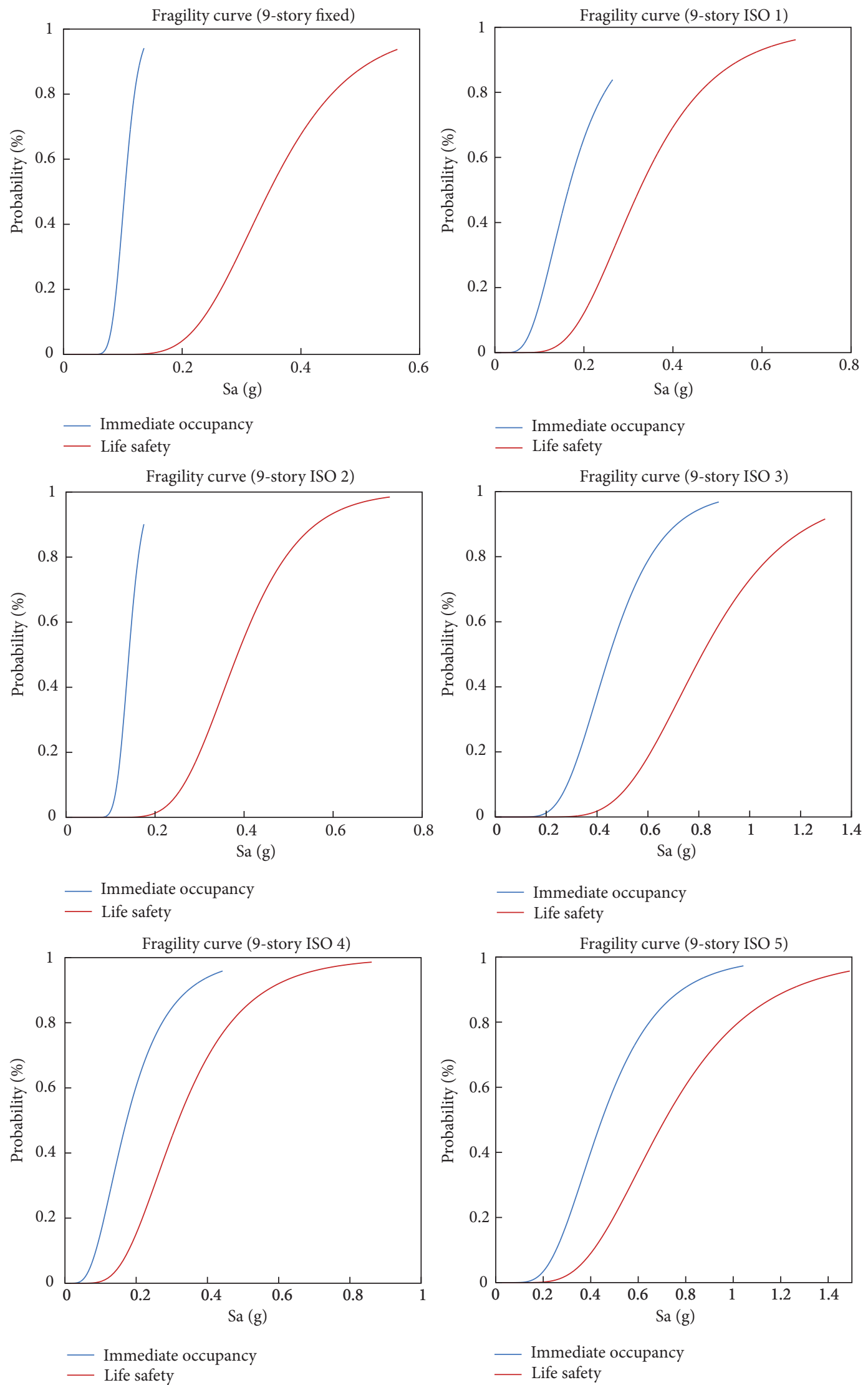

FIGURE 12: Continued. 

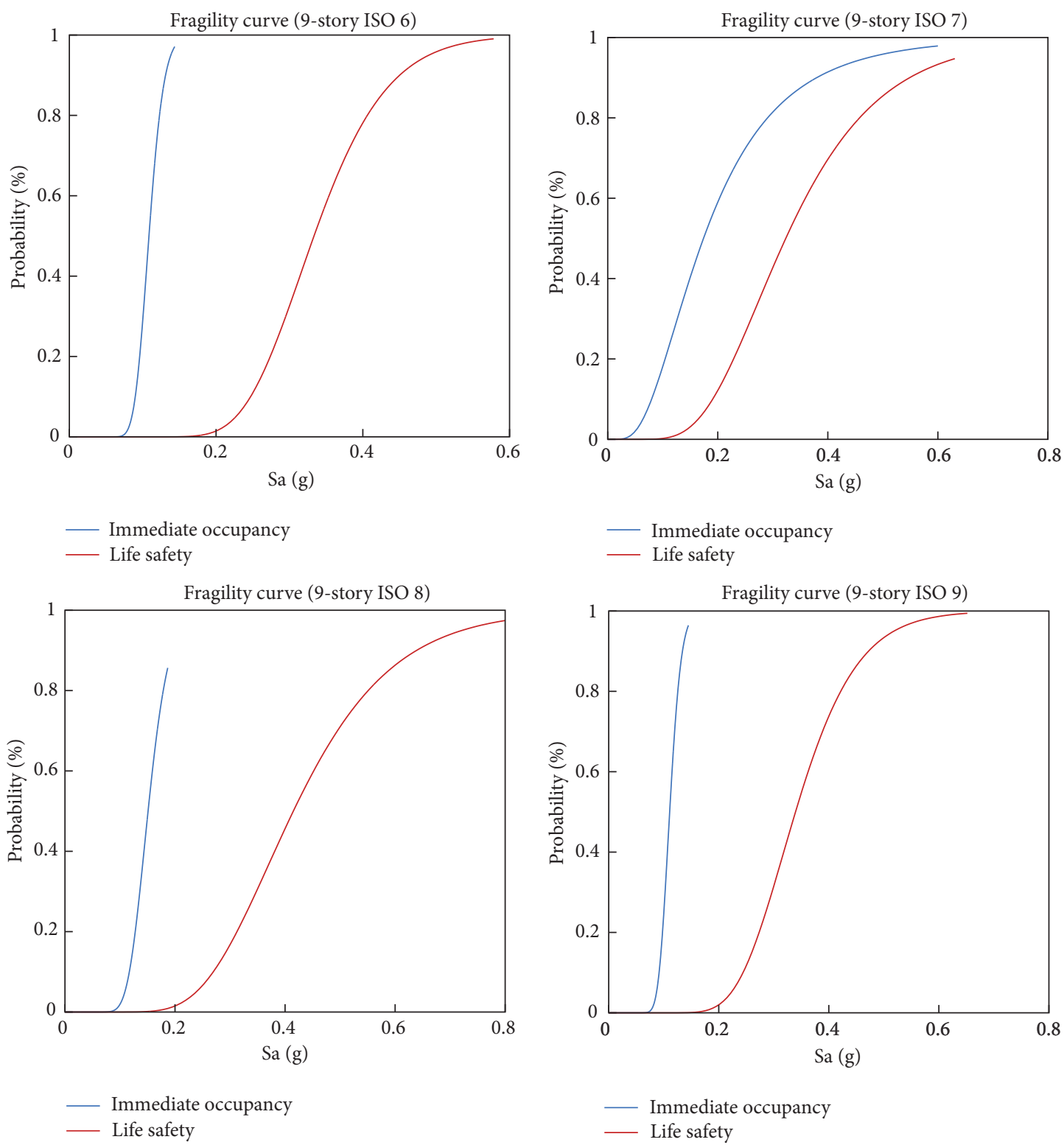

FIGURE 12: Fragility curves of 9 -story frame (ISO 1 to 9 are related to damping ratios $0.1,0.26,0.48,0.19,0.52,0.78,0.3,0.71$, and 1.0 , resp.).

starts to work in constant Sa and higher relative displacements, the inverse results are obtained in comparison of former one in LS fragility curves, though by increasing isolator damping, the exceedance probability of LS performance level is decreased, that is, equivalent to $0.25 \%$ relative displacement.

(iv) The time period of structure in the fixed state is 1 second and when the structure is equipped with LRB damper, time period of structure increases.

(v) According to the results, it is seen that, by increasing damping in structures, the $\mathrm{Sa}$ analogous intensity parameter increases with immediate occupancy performance level and life safety and furthermore by increasing the time period of designed isolator, this amount decreases. (vi) In 3-story building, with design time period of $2.5 \mathrm{sec}-$ onds, by increasing damping the annual exceedance probability increases in the performance level IO and decreases in LS, respectively, where in both states these amounts are less than the amounts without isolator.

(vii) By increasing damping, the annual exceedance probability increases and decreases in the performance levels of IO and LS, respectively, where in both states this amount is less than the amount without isolator.

(viii) In both 3- and 9-story structure in the IO state, the increase of damping gets the exceedance probability increased. Maybe this is because the area of entered force is low and the damper does not work so much. 

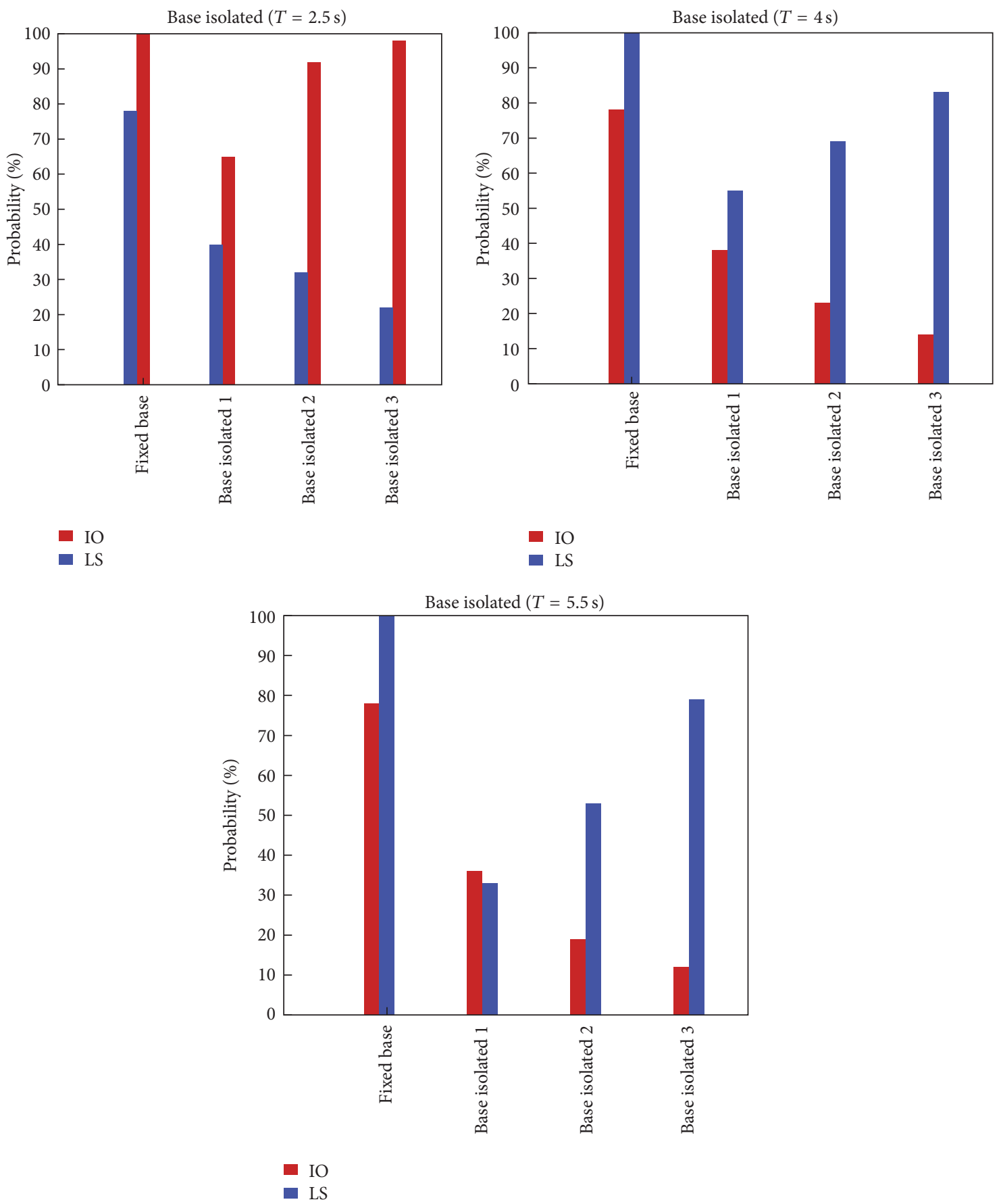

FIGURE 13: Annual exceedance probability of 9-story frame at IO and LS levels.

But in the LS state, the isolator has good decreasing effect, because the entered force is great.

(ix) Moreover, according to the obtained results it is clear that, in the IO performance level, the amount of damage probability reduction is less in 9-story structure; it means the isolator shows the better performance in 3-story structure. But in the LS performance level, the isolator significantly decreases the amount of damage in 9-story structure in comparison with 3story structure. For example, in design time period of 2.5 seconds, the exceedance probability is $26 \%$ and $22 \%$, respectively, in 3- and 9-story structures.

(x) With respect to results, it can be said that in 3story structure with design time period of $2.5,4$, and 5.5 seconds by increasing damping the annual exceedance probability increases and decreases in the performance levels IO and LS, respectively, whilst in both states these amounts are less than the amounts of fixed base structure. Although structure has an appropriate performance rather than the fixed base 
TABLE 5: The amounts of annual exceedance probability; 9-story structure.

(a) Period $=2.5 \mathrm{~s}$

\begin{tabular}{lcccc}
\hline Structure & Fixed base & $\begin{array}{c}\text { Base } \\
\text { isolated 1 } \\
(2.5 \mathrm{~s})\end{array}$ & $\begin{array}{c}\text { Base } \\
\text { isolated 2 } \\
(2.5 \mathrm{~s})\end{array}$ & $\begin{array}{c}\text { Base } \\
\text { isolated 3 } \\
(2.5 \mathrm{~s})\end{array}$ \\
\hline Period(s) & 2 & 3 & 2.65 & 2.52 \\
Prob(IO) & $100 \%$ & $65 \%$ & $92 \%$ & $98 \%$ \\
Prob(LS) & $78 \%$ & $40 \%$ & $32 \%$ & $22 \%$ \\
\hline
\end{tabular}

(b) Period $=4 \mathrm{~s}$

\begin{tabular}{lcccc}
\hline Structure & Fixed base & $\begin{array}{c}\text { Base } \\
\text { isolated 1 } \\
(4 \mathrm{~s})\end{array}$ & $\begin{array}{c}\text { Base } \\
\text { isolated 2 } \\
(4 \mathrm{~s})\end{array}$ & $\begin{array}{c}\text { Base } \\
\text { isolated 3 } \\
(4 \mathrm{~s})\end{array}$ \\
\hline Period(s) & 2 & 3.17 & 2.72 & 2.62 \\
Prob(IO) & $100 \%$ & $55 \%$ & $69 \%$ & $83 \%$ \\
Prob(LS) & $78 \%$ & $38 \%$ & $23 \%$ & $14 \%$ \\
\hline
\end{tabular}

(c) Period $=5.5 \mathrm{~s}$

\begin{tabular}{lcccc}
\hline Structure & Fixed base & $\begin{array}{c}\text { Base } \\
\text { isolated 1 } \\
(5.5 \mathrm{~s})\end{array}$ & $\begin{array}{c}\text { Base } \\
\text { isolated 2 } \\
(5.5 \mathrm{~s})\end{array}$ & $\begin{array}{c}\text { Base } \\
\text { isolated 3 } \\
(5.5 \mathrm{~s})\end{array}$ \\
\hline Period(s) & 2 & 3.3 & 2.87 & 2.72 \\
Prob(IO) & $100 \%$ & $33 \%$ & $53 \%$ & $79 \%$ \\
Prob(LS) & $78 \%$ & $36 \%$ & $19 \%$ & $12 \%$ \\
\hline
\end{tabular}

structure in IO performance level, by increasing damping, the amounts of annual exceedance probability are increased. In other words, the isolator shows better performance in low damping, and this situation is opposite the state that happens in LS; it means that, in higher damping, the isolator shows the better performance from itself.

The results demonstrate that, by increasing the design time period, the amount of damage probability decreases in comparison with less design time period and the isolator shows better performance.

\section{Conflicts of Interest}

The authors declare that they have no conflicts of interest.

\section{Acknowledgments}

This research was supported by Support for Infrastructure and Transportation Technology Commercialization Program funded by Ministry of Land, Infrastructure and Transport of Korean Government (Grant no. 15TBIP-C093001-01).

\section{References}

[1] Applied Technology Council, Ed., ATC-40: Seismic Evaluation and Retrofit of Concrete Buildings, 1996.

[2] Federal Emergency Management Agency, Ed., FEMA 273: Guidelines for Seismic Rehabilitation of Buildings, 1997.
[3] Federal Emergency Management Agency, Ed., FEMA 350: Recommended Seismic Design Criteria for New Steel MomentFrame Buildings, 2000.

[4] Federal Emergency Management Agency, FEMA 356: Prestandard and Commentary for the Seismic Rehabilitation of Buildings, Federal Emergency Management Agency, 2000.

[5] Federal Emergency Management Agency, Ed., FEMA P695: Quantification of Building System Performance and Response Parameters, 2009.

[6] C. P. Providakis, "Effect of LRB isolators and supplemental viscous dampers on seismic isolated buildings under near-fault excitations," Engineering Structures, vol. 30, no. 5, pp. 1187-1198, 2008.

[7] T. Andriono and A. J. Carr, "A simplified earthquake resistant design method for base isolated multistorey structures," Bulletin of the New Zealand Society for Earthquake Engineering, vol. 24, no. 3, pp. 238-250, 1991.

[8] T. C. Liauw, Q. L. Tian, and Y. K. Cheung, "Structures on sliding base subject to horizontal and vertical motions," Journal of Structural Engineering (United States), vol. 114, no. 9, pp. 21192129, 1988.

[9] S. L. Kramer, Geotechnical Earthquake Engineering, PrenticeHall, 1996.

[10] H. Shakib and A. Fuladgar, "Response of pure-friction sliding structures to three components of earthquake excitation," Computers and Structures, vol. 81, no. 4, pp. 189-196, 2003.

[11] M. AllamehZadeh, "Discrimination analysis of earthquakes and man-made events using ARMA coefficients determination by artificial neural networks," Natural Resources Research, vol. 20, no. 4, pp. 367-375, 2011.

[12] L. Dong, X. Li, and G. Xie, "Nonlinear methodologies for identifying seismic event and nuclear explosion using random forest, support vector machine, and naive Bayes classification," Abstract and Applied Analysis, vol. 2014, Article ID 459137, 8 pages, 2014.

[13] L.-J. Dong, J. Wesseloo, Y. Potvin, and X.-B. Li, "Discriminant models of blasts and seismic events in mine seismology," International Journal of Rock Mechanics and Mining Sciences, vol. 86, pp. 282-291, 2016.

[14] C. S. Tsai, "Advanced base isolation systems for light weight equipments," in Earthquake Resistant Structures-Design, Assessment and Rehabilitation, pp. 79-130, InTech, 2012.

[15] J. W. Hu, "Response of seismically isolated steel frame buildings with sustainable lead-rubber bearing (LRB) isolator devices subjected to near-fault (NF) ground motions," Sustainability (Switzerland), vol. 7, no. 1, pp. 111-137, 2015.

[16] J. Zhang and Y. Huo, "Evaluating effectiveness and optimum design of isolation devices for highway bridges using the fragility function method," Engineering Structures, vol. 31, no. 8, pp. 1648-1660, 2009.

[17] L. K. Vasiliadis, "Seismic evaluation and retrofitting of reinforced concrete buildings with base isolation systems," Earthquake and Structures, vol. 10, no. 2, pp. 293-311, 2016.

[18] J. Seo and J. W. Hu, "Seismic response and performance evaluation of self-centering LRB isolators installed on the CBF building under NF ground motions," Sustainability, vol. 8, no. 2, pp. 1-22, 2016.

[19] M. A. Komur, "Soft-story effects on the behavior of fixed-base and LRB base-isolated reinforced concrete buildings," Arabian Journal for Science and Engineering, vol. 41, no. 2, pp. 381-391, 2016. 
[20] J. W. Hu, "Seismic analysis and parametric study of SDOF leadrubber bearing (LRB) isolation systems with recentering shape memory alloy (SMA) bending bars," Journal of Mechanical Science and Technology, vol. 30, no. 7, pp. 2987-2999, 2016.

[21] M. Kumar, A. S. Whittaker, and M. C. Constantinou, "Response of base-isolated nuclear structures to extreme earthquake shaking," Nuclear Engineering and Design, vol. 295, pp. 860-874, 2015.

[22] M. K. Sharbatdar, S. R. Hoseini Vaez, G. Ghodrati Amiri, and H. Naderpour, "Seismic response of base-isolated structures with LRB and FPS under near fault ground motions," Procedia Engineering, vol. 14, pp. 3245-3251, 2011.

[23] R. L. Mayes and F. Naeim, "Design of structures with seismic isolation," in The Seismic Design Handbook, pp. 723-755, Springer, 2001.

[24] Y. Wang, "Fundamentals of seismic isolation," in Proceedings of the International Training Programs for Seismic Design of Building Structures, pp. 139-149, Taipei, Taiwan, 2003.

[25] D. Vamvatsikos, Seismic performance, capacity and reliability of structures as seen through incremental dynamic analysis [Ph.D. thesis], Stanford University, 2002.

[26] F. Colangelo, "A simple model to include fuzziness in the seismic fragility curve and relevant effect compared with randomness," Earthquake Engineering and Structural Dynamics, vol. 41, no. 5, pp. 969-986, 2012.

[27] Y. Ohtori, R. E. Christenson, B. F. Spencer Jr., and S. J. Dyke, "Benchmark control problems for seismically excited nonlinear buildings," Journal of Engineering Mechanics, vol. 130, no. 4, pp. 366-385, 2004.

[28] F. Naeim and J. M. Kelly, Design of Seismic Isolated Structures: From Theory to Practice, John Wiley \& Sons, Hoboken, NJ, USA, 1999.

[29] F. McKenna, G. L. Fenves, and M. H. Scott, Open System for Earthquake Engineering Simulation, OpenSees, 2000.

[30] N. Shome, Probabilistic seismic demand analysis of nonlinear structures [Ph.D. thesis], Stanford University, 1999.

[31] J. Seo, J. W. Hu, and B. Davaajamts, "Seismic performance evaluation of multistory reinforced concrete moment resisting frame structure with shear walls," Sustainability, vol. 7, no. 10, pp. 14287-14308, 2015. 


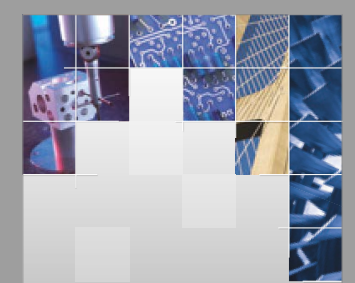

\section{Enfincering}
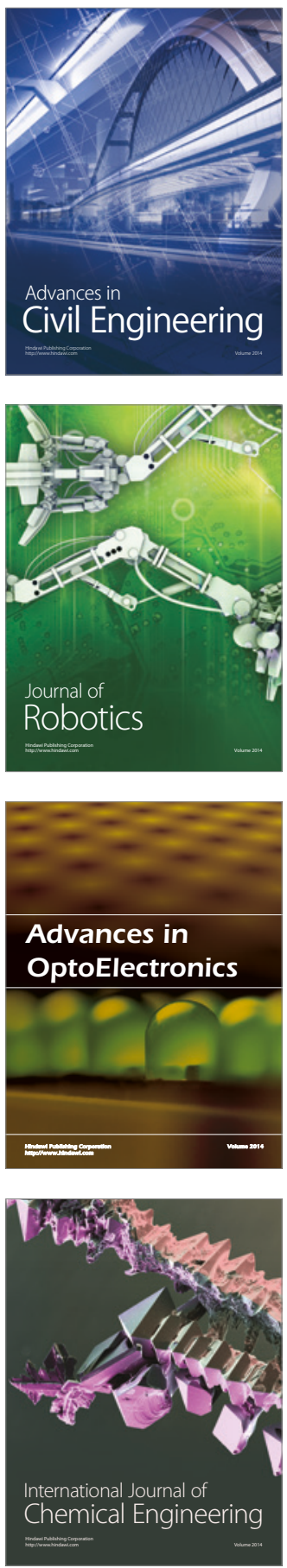

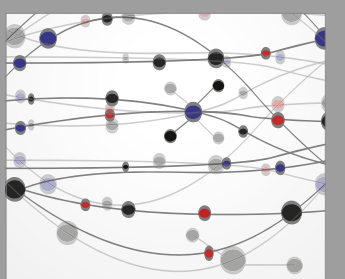

The Scientific World Journal

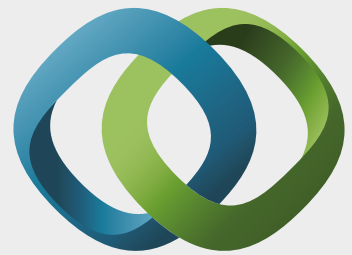

\section{Hindawi}

Submit your manuscripts at

https://www.hindawi.com
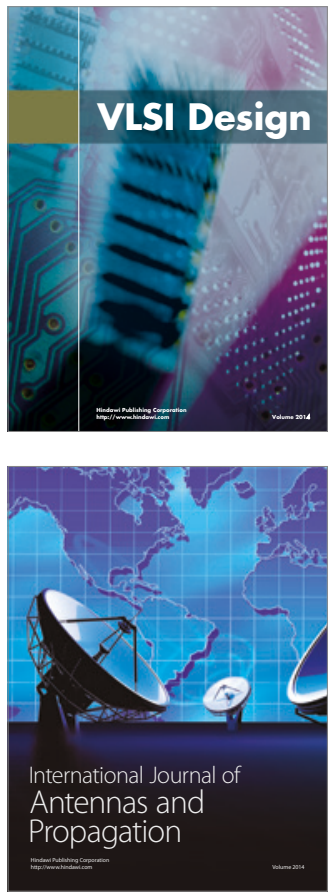

\section{Rotating}

Machinery
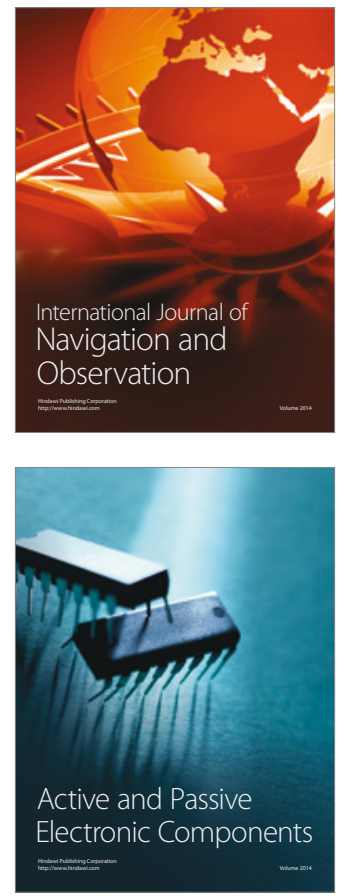
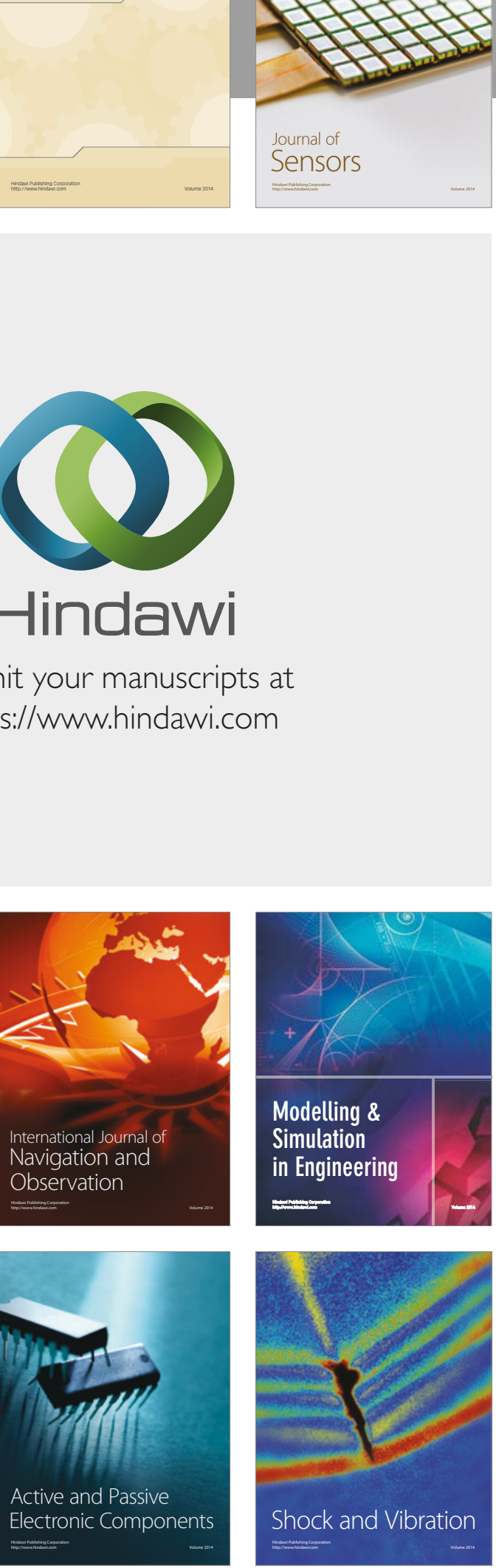
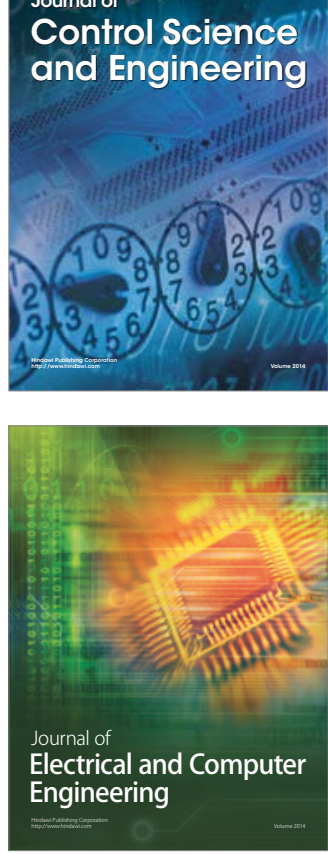

Distributed

Journal of

Control Science

and Engineering
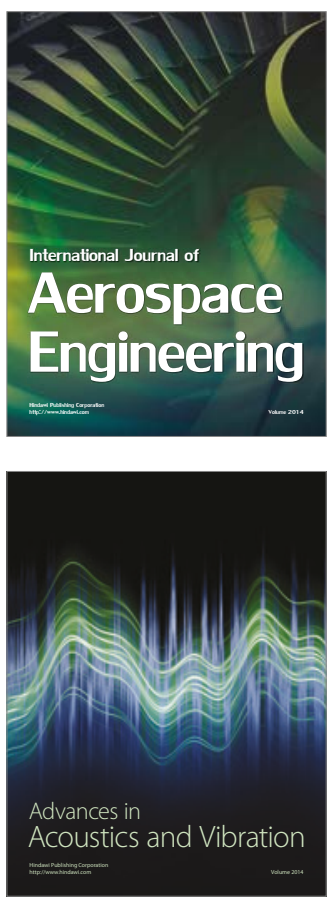

Sensor Networks 